\title{
432183
}

\section{Benefits of Swept and Leaned Stators for Fan Noise Reduction}

Richard P. Woodward, David M. Elliott, Christopher E. Hughes, and Jeffrey J. Berton Lewis Research Center, Cleveland, Ohio 
Since its founding, NASA has been dedicated to the advancement of aeronautics and space science. The NASA Scientific and Technical Information (STI) Program Office plays a key part in helping NASA maintain this important role.

The NASA STI Program Office is operated by Langley Research Center, the Lead Center for NASA's scientific and technical information. The NASA STI Program Office provides access to the NASA STI Database, the largest collection of aeronautical and space science STI in the world. The Program Office is also NASA's institutional mechanism for disseminating the results of its research and development activities. These results are published by NASA in the NASA STI Report Series, which includes the following report types:

- TECHNICAL PUBLICATION. Reports of completed research or a major significant phase of research that present the results of NASA programs and include extensive data or theoretical analysis. Includes compilations of significant scientific and technical data and information deemed to be of continuing reference value. NASA's counterpart of peerreviewed formal professional papers but has less stringent limitations on manuscript length and extent of graphic presentations.

- TECHNICAL MEMORANDUM. Scientific and technical findings that are preliminary or of specialized interest, e.g., quick release reports, working papers, and bibliographies that contain minimal annotation. Does not contain extensive analysis.

- CONTRACTOR REPORT. Scientific and technical findings by NASA-sponsored contractors and grantees.
- CONFERENCE PUBLICATION. Collected papers from scientific and technical conferences, symposia, seminars, or other meetings sponsored or cosponsored by NASA.

- SPECIAL PUBLICATION. Scientific, technical, or historical information from NASA programs, projects, and missions, often concerned with subjects having substantial public interest.

- TECHNICAL TRANSLATION. Englishlanguage translations of foreign scientific and technical material pertinent to NASA's mission.

Specialized services that complement the STI Program Office's diverse offerings include creating custom thesauri, building customized data bases, organizing and publishing research results... even providing videos.

For more information about the NASA STI Program Office, see the following:

- Access the NASA STI Program Home Page at http://www.sti.nasa.gov

- E-mail your question via the Internet to help@sti.nasa.gov

- Fax your question to the NASA Access Help Desk at (301) 621-0134

- Telephone the NASA Access Help Desk at (301) 621-0390

- Write to:

NASA Access Help Desk

NASA Center for AeroSpace Information 7121 Standard Drive Hanover, MD 21076 


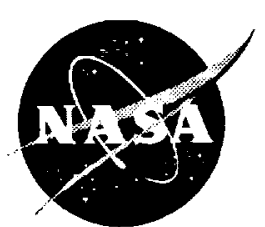

\section{Benefits of Swept and Leaned Stators for Fan Noise Reduction}

Richard P. Woodward, David M. Elliott, Christopher E. Hughes, and Jeffrey J. Berton Lewis Research Center, Cleveland, Ohio

Prepared for the

37th Aerospace Sciences Meeting and Exhibit

sponsored by the American Institute of Aeronautics and Astronautics

Reno, Nevada, January 11-14, 1999

National Aeronautics and

Space Administration

Lewis Research Center 
This report is a preprint of a paper intended for presentation at a conference. Because of changes that may be made before formal publication, this preprint is made available with the understanding that it will not be cited or reproduced without the permission of the author.

Available from

NASA Center for Aerospace Information 7121 Standard Drive

Hanover, MD 21076

Price Code: A03

National Technical Information Service 5285 Port Royal Road Springfield, VA 22100

Price Code: A03 


\title{
BENEFITS OF SWEPT AND LEANED STATORS FOR FAN NOISE REDUCTION
}

\author{
Richard P. Woodward, David M. Elliott, \\ Christopher E. Hughes, and Jeffrey J. Berton \\ National Aeronautics and Space Administration \\ Lewis Research Center \\ Cleveland, Ohio 44135
}

$\underline{\text { Abstract }}$

An advanced high bypass ratio fan model was tested in the NASA Lewis Research Center $9 \times 15$-Foot Low Speed Wind Tunnel. The primary focus of this test was to quantify the acoustic benefits and aerodynamic performance of sweep and lean in stator vane design. Three stator sets were used for this test series. A conventional radial stator was tested at two rotor-stator axial spacings. Additional stator sets incorporating sweep + lean, and sweep only were also tested. The hub axial location for the swept + lean, and sweep only stators corresponded to the location of the radial stator at the upstream rotor-stator spacing, while the tip axial location of these modified stators corresponded to the radial stator axial position at the downstream position. The acoustic results show significant reductions in both rotor-stator interaction noise and broadband noise beyond what could be achieved through increased axial spacing of the conventional, radial stator. Theoretical application of these results to acoustically quantify a fictitious 2 -engine aircraft and flight path suggested that about 3 EPNdB could be achieved through incorporation of these modified stators. This reduction would represent a significant portion of the 6 EPNdB noise goal of the current NASA Advanced Subsonic Technology (AST) initiative relative to that of 1992 technology levels. A secondary result of this fan test was to demonstrate the ability of an acoustic barrier wall to block aft-radiated fan noise in the wind tunnel, thus revealing the acoustic structure of the residual inletradiated noise. This technology should prove valuable toward better understanding inlet liner design, or wherever it is desirable to eliminate aft-radiated noise from the fan acoustic signature.
Introduction

A major source of aircraft engine noise comes from interaction of the rotor viscous wake with the exit guide vanes, or stators. The most prominent component of this interaction noise are tones at multiples of the rotor blade passage frequency, although there also exists a broadband component of this rotor-stator noise. Traditional methods of reducing this interaction noise have been to select blade/vane ratios to satisfy the cut off criterion for propagation of the fundamental rotor tone ${ }^{l}$ and increased axial spacing between the rotor and stator. ${ }^{2}$ Increased rotor-stator axial spacing may somewhat degrade the fan aerodynamic performance and increase the overall engine weight.

The current Advanced Subsonic Technology (AST) noise initiative calls for a 6 EPNdB (Effective Perceived Noise) engine noise reduction relative to 1992 technology levels to be achieved by 1999. This work calls for a comprehensive understanding of engine noise generation mechanisms accompanied by analylic and experimental validations.

Stator vane lean and/or sweep have been suggested as a mechanism to reduce the severity of the rotor wake interaction with the stator vane. Vane sweep is the axial displacement of the vane with radius such that the tip region is further downstream than the hub. Correspondingly, lean is a circumferential displacement of the vane stacking line relative to the radial direction. Both of these stator modifications have been proposed as a means to reduce the stator response to the rotor downwash, thereby reducing the rotor/stator acoustic response. Kazen ${ }^{3}$ demonstrated rotor/stator interaction tone reductions associated with a stator leaned $30^{\circ}$ in the direction of fan 
rotation. Noise reductions in the $2 \mathrm{BPF}$ tone from 1.5 to $3.5 \mathrm{~dB}$ with the leaned stator were observed in this study.

Analytical studies ${ }^{4}$ have suggested that both stator lean and sweep, if properly applied, may significantly reduce rotor/stator interaction tone noise. Optimal stator lean and sweep offers the possibility of reducing the overall engine weight through decreased axial rotor-stator spacing or achieving additional tone noise reduction for a particular rotor-stator spacing.

An advanced high bypass subsonic fan model incorporating stator sweep and lean was designed and built by the Allison Engine Company under contract to NASA Lewis Rescarch Center (Contract NAS3-25950). The Allison fan was tested in the NASA Lewis 9- by 15-Foot Low Speed Wind Tunnel ${ }^{5-7}(9 \times 15$ LSWT), which is located in the low-speed return leg of the 8 - by 6-Foot Supersonic Wind Tunnel $(8 \times 6$ SWT $)$. These fan tests were conducted at a freestream Mach Number of 0.10 . The test section walls are acoustically treated to provide anechoic conditions down to a frequency of $250 \mathrm{~Hz}$, which is lower than the range of test fan acoustic tones.

The emphasis of this fan test was to evaluate the aeroacoustic performance of the swept + leaned, and swept only stator relative to that of a baseline radial stator. All stators had the same vane number and were designed for equivalent aerodynamic performance. Acoustic data are presented in terms of sideline directivities and spectra. These data were also used to generate flyover and sideline EPNL estimates for a fictitious two-engine aircraft and flight path to give an estimate of the EPNL benefit associated with these stator modifications.

\section{Description of Fan Test}

ResearchFan. An advanced high bypass subsonic fan model incorporating stator lean and sweep was designed and built by the Allison Engine Company under contract to NASA Lewis. ${ }^{7}$ Figure 1 is a photograph of the fan installed in the NASA Lewis $9 \times 15$ LSWT. The fan was tested at a freestream Mach Number of 0.10 in the test section, which is sufficient to achieve acoustic flight effect $^{8}$ and provides acoustic data representative of takeoff/ approach operation. All data were taken at $0^{\circ}$ fan axis angle of attack.

The Allison fan was driven by the NASA Lewis Ultra High Bypass (UHB) drive rig. The UHB drive rig was powered by a high pressure air turbine drive with the drive air and instrumentation supplied through the support strut, shown in Fig. 1. The drive turbine exhaust air was ducted downstream through an acoustically treaded diffuser and exited the end of the treated test section. There was little indication of acoustic contamination of the aft fan data from the turbine exhaust.

Table I shows design characteristics of the Allison Fan. The 18 blade rotor had a diameter of $55.9 \mathrm{~cm}$ (22 in.).
Three research stator sets were fabricated - a conventional radial stator and modified stators with sweep + lean, and sweep only. (A leaned only stator set would have been desirable, but was eliminated from the contract due to cost considerations.) All stator sets had 42 vanes and were designed for equivalent fan stage aerodynamic performance. The fan stage did not have a core flow simulator. The baseline stator configuration was with the radial stator at the closer axial rotor-stator spacing (Fig. 2). The radial stator was also tested at a larger rotor-stator axial spacing. The swept + leaned, and swept only stators were designed such that the hub was located at the same axial rotor-stator spacing as the baseline stator, and the tip was located at an axial location corresponding to the radial stator at the larger axial spacing, (Fig. 3). These stators were designed with $30^{\circ}$ of sweep and $30^{\circ}$ of lean. The swept + leaned stator was leaned in the direction of rotor rotation.

Figures 4 to 7 are photographs of the partially assembled fan stage. Figure 4 is a photograph of the stage showing the rotor and the swept and leaned stator. Figure 5 shows the rotor and the swept-only stator. Figure 6 is a downstream view of the swept and leaned stator. Figure 7 is a downstream view of the swept and leaned stator seen through the rotor.

Anechoic Wind Tunneland Acoustic Instrumentation. The NASA Lewis $9 \times 15$ LSWT is located in the low speed return leg of the $8 \times 6 \mathrm{SWT}$ (Fig. 8). The tunnel test section walls, floor and ceiling had acoustic treatment to produce an anechoic test environment. Figure 9 is a sketch of the test fan installed in the $9 \times 15 \mathrm{LSWT}$. Sideline acoustic data were acquired with a computer-controlled translating microphone probe (also seen in the photograph of Fig. 1) and with three aft microphone assemblies mounted to the tunnel floor. The translating microphone probe acquired data at 48 sideline geometric angles from 27.2 to $134.6^{\circ}$ relative to the fan rotor plane. The translating probe traverse was at $224 \mathrm{~cm}$ (88 in.) from the fan rotational axis (four fan diameters). A wall microphone assembly placed a reference microphone adjacent to the translating probe home position (134.6 $6^{\circ}$, maximum aft travel). Three fixed microphone assemblies were mounted to the tunnel flow at this same axial position to acquire aft acoustic data at geometric angles of 140,150 , and $160^{\circ}$. The acoustic data were acquired through a digital computer system and stored for post-run analysis.

\section{$\underline{\text { Results and Discussion }}$}

\section{Aerodynamic Performance}

The three fan stator sets were designed for equivalent aerodynamic performance. Figures 10 and 11 present a brief overview of the fan performance with the three stator sets. The baseline radial stator showed the highest corrected 
weight flow as a function of corrected fan speed, with the swept + leaned stator showing the Iowest weight flow value (Fig. 10). However, the weight flow differences between stator sets at the same fan speed is relatively small, on the order of 1 to 1.5 percent.

Figure 11 shows the percent system loss as a function of percent corrected fan speed for the fan with swept + leaned, and swept only stators. The results shown are normalized to the baseline stator configuration performance. The system losses with the swept + leaned stator were 2.5 to three percent greater than losses with the swept only stator. These losses are thought to be associated with the high pressure and velocities due to the supercharged nature of the flow in the hub region without a core simulator. These flow conditions appear to be causing large separated regions on the stators that increase system losses. In addition, large viscous wall losses are associated with the corner flow at the stator hub and tip for the swept + leaned stator. A somewhat different design methodology was employed for the swept only stator, which was partially optimized using area ruling at the tip region to help relieve the high velocity region there caused by the flow stacking up in the outboard region of the stator. Consequently, the swept only stator showed less system losses.

These limited aerodynamic results are included to better understand the associated acoustic performance of the fan with the non-radial stators. A point for consideration is that the swept + leaned and swept only stator designs were not optimized for the fan or design point performance. These were technology demonstrator, proof-of-concept designs, and the aerodynamic performance losses associated with them are not representative of the performance potential for this technology. Encouragingly, acoustic benefits associated with the swept + leaned stator are in spite of the somewhat higher system losses associated with this stator. A swept + leaned stator with lower system losses may show additional noise reduction relative to the results presented in this report.

\section{Acoustic Performance}

All of the fan acoustic data were acquired at a tunnel test section velocity of $0.10 \mathrm{Mach}$. Sideline data are presented in terms of emission angles. The emission angles are related to the geometric, or observed angles by the relationship:

$$
\Theta_{\mathrm{em}}=\Theta_{\mathrm{geom}}-\sin ^{-1}\left(M_{\mathrm{o}} \sin \Theta_{\mathrm{geom}}\right)
$$

where $\Theta_{\mathrm{em}}$ and $\Theta_{\text {geom }}$ are, respectively, the emission and observed sideline angles, and $M_{o}$ is the test section Mach number. The observed angles for the sideline translating microphone probe are then 25 to $130^{\circ}$, and the three fixed microphones measure aft observed angles of 136, 147, and $158^{\circ}$. This angular range was sufficient to define the sideline noise profile for this aft-dominated fan for subsequent EPNL calculations.

Digital acoustic data were processed as constant bandwidth spectra. Spectra were acquired and averaged at each translating probe or fixed mic position with 6 and $59 \mathrm{~Hz}$ bandwidths. These constant bandwidth spectra were electronically merged and used to generate $1 / 3$ octave spectra. The results presented herein are in terms of both constant bandwidth and $1 / 3$ octave spectra.

Swept + leaned, and swept only stators were expected to reduce rotor-stator interaction tones by relieving the severity of the rotor wake interaction with the stator vanes. An additional observed benefit was a reduction in fan broadband noise. Two techniques were employed to separate the interaction tone and broadband components of the noise. A software technique was used with the digital data reduction to produce constant bandwidth, and consequently, 1/3 octave spectra with minimal interaction tone content. This technique investigated the spectra at interaction tone frequencies and eliminated tones which were $6 \mathrm{~dB}$ or more above adjacent spectral levels. Broadband levels at the first four interaction tone frequencies were also deduced by manually inspecting selected constant bandwidth spectral arrays.

Effective Perceived Noise Levels. The effective perceived noise level (EPNL) provides a subjective measure of the aircraft flyover and sideline noise levels. This value is derived from the flyover or sideline sound pressure level profiles and is a function of frequency, duration, and tone content.

Effective perceived noise levels were calculated for a fictitious 2-engine aircraft and flight profile based on the Allison fan model acoustic results. A 3.5 scaling factor was assumed, and calculations were made for a $0.25 \mathrm{Mach}$ flight speed. EPNL calculations were made for the full $1 / 3$ octave spectra, and for representative broadband noise using the $1 / 3$ octave spectra with the interactions tones electronically removed. FAR 36 Stage 3 sideline EPNL calculations are for an observer on a $450 \mathrm{~m}$ (1476 ft) sideline. EPNLs were evaluated every $30.5 \mathrm{~m}$ (100 ft) along this line to ensure that the sideline noise reported was indeed the maximum level. FAR36 Stage 3 cutback EPNL calculations are for an observer $6500 \mathrm{~m}(21.325 \mathrm{ft})$ from brake release in line with the runway.

Figure 12 shows the aircraft EPNL on the $450 \mathrm{~m}$ (1476 ft) sideline. Although the throttle setting used at takeoff would be at or near the fan design speed, the sideline noise is evaluated for the range of speeds investigated for illustrative purposes. There is about a 1.5 EPNdB decrease associated with moving the radial stator from the forward position to the aft position at all fan speeds except 110 percent of design, where the change in noise level is negligible. However, the addition of sweep 
+ lean, or sweep only results in about a 3 EPNdB reduction from noise levels relative to that for the forward radial stator at fan speeds up to about 75 percent of design. The sweep only stator maintains this $3 \mathrm{EPNdb}$ reduction relative to baseline in the mid speed range of 75 to 95 percent design speed. The swept + leaned stator showed the most noise reduction at design and above fan speeds. Similar results are seen for the flyover EPNL calculations of Fig. 13. The use of a range of fan speeds is more applicable for flyover EPNL, since a throttle cutback is often used in that segment. The analytical EPNL predictions for sideline and flyover observers differ due to geometric inputs to the extra ground attenuation and ground reflection models. These differences, however, do not significantly affect the trends with respect to fan speed. Thus, although the magnitudes of the sideline and flyover EPNLs are of course different, the trends are nearly identical.

The relatively poor performance of the $s w e p t+$ leaned stator at fan speeds near 90 percent design may be explained by the relatively lower aerodynamic performance of that stator (Fig. 11). System losses associated with the swept + leaned stator are thought to arise from less than optimal flow near the hub and tip regions. It is quite possible that refinements in the acrodynamic design of the swept + leaned stator would result in superior performance for this concept throughout the fan speed range.

The theoretical study of Ref. 4 concludes that sweep should be most beneficial at takeoff conditions, while lean should be most beneficial at approach conditions. This reference does conclude that combining sweep and lean should be complementary toward overall noise reduction. The results of Figs. 12 and 13 are only marginally supportive of this prediction. It would appear from the data that sweep alone, rather than sweep + lean, achieved essentially all of the noise reduction at the lower fan speeds. At the higher fan speeds additional noise reduction was achieved with sweep + lean beyond what was observed by sweep only. However, it is clear from these figures that incorporation of stator sweep + lean results in significant noise reductions throughout the fan operating range relative to what could be achieved through simply increasing the axial spacing of the radial stator.

Figures 14 and 15 present corresponding broadband results for the fictitious 2-engine aircraft based on the acoustic data with the rotor-stator interaction tones electronically removed. This computer tone removal technique only removed tones which were $5 \mathrm{~dB}$ or more above the adjacent broadband, and as such, may not fully represent the spectral broadband levels. The overall pattern of the data is similar to what was generated from the inclusive spectra (Figs. 12 and 13), although the noise reductions are somewhat less. In particular, noise reductions associated with increasing the axial spacing of the radial stator are only seen at fan speeds below 85 percent of design. Reference 2 notes that experimental broadband noise levels showed little change with rotor-stator spacing (for a radial stator). This may be another indication that there is some tonal contamination in the lower speed results of Figs. 14 and 15.

Sound Pressure Level Directivities. Sideline sound pressure level (SPL) directivities provide a useful tool for evaluating acoustic differences associated with changes in the stator configuration. These directivities were achieved by combining results from the traverse microphone and the three aft fixed microphones, resulting in $224 \mathrm{~cm}$ (88 in.) sideline directivities for 25 to $158^{\circ}$ emission angles relative to the fan upstream axis and centered on the fan rotor plane. These results are for constant bandwidth $(59 \mathrm{~Hz})$ spectra.

Figure 16 shows representative SPL directivities for the four test configurations. These results are for the fan operating at 50 percent of corrected design speed. These data are for the 2BPF tone, which falls within the $3150 \mathrm{~Hz}$ $1 / 3$ octave band. Advanced high bypass ratio fans, such as that reported herein, tend to have aft-dominated directivities. The results of figure 16 clearly show that there is a significant noise reduction associated with increased radial stator spacing, and additional noise benefits to bc realized with a swept + leaned, and swept only stator.

The noise reduction trends shown in Fig. 16, are more easily understood in terms of changes in noise level relative to that observed for the baseline radial stator in the upstream position. The sound pressure level (SPL) directivities for the four stator configurations will now be explored in this manner at four representative fan speeds. Constant bandwidth $(59 \mathrm{~Hz})$ spectra were used for this analysis to facilitate separation of the rotor-stator interaction tone from adjacent broadband noise. The following test conditions will be reported:

$\begin{array}{lcc}\text { Percentcorrecied } & \text { Corrected rotor tangential } & \text { Tip Relative Mach } \\ \text { fan speed } & & \text { tip speed } \\ 50 \text { (approach) } & 152 \mathrm{~m} / \mathrm{s}(500 \mathrm{ft} / \mathrm{s}) & 0.507 \\ 84(\text { takeofn } & 256 \mathrm{~m} / \mathrm{s}(840 \mathrm{ft} / \mathrm{s}) & 0.900 \\ 100(\text { sideline }) & 305 \mathrm{~m} / \mathrm{s}(1000 \mathrm{ft} / \mathrm{s}) & 1.080 \\ 110 & 335 \mathrm{~m} / \mathrm{s}(1100 \mathrm{ft} / \mathrm{s}) & 1.187\end{array}$

Results for each test speed will be presented in terms of representative spectra at a $126^{\circ}$ emission angle followed with directivities showing the tone and broadband reductions relative to noise levels observed for the baseline radial stator in the forward axial position. The broadband levels at rotor-stator interaction frequencies were manually extracted through inspection of the individual noise spectra and should provide a reasonably good representation of these levels.

Figure 17 compares spectra acquired at $126^{\circ}$ emission angle along the $224 \mathrm{~cm}$ (88 in.) sideline for the fan 
operating at 50 percent design speed. The fundamental rotor-stator interaction tone (BPF) is cut-off and essentially not present in the spectra. Strong 2 and $3 B P F$ tones are evident for the radial stator in the upstream position. These overtones are essentially attenuated either by moving the radial stator to the aft position or employing sweep and/or lean. However, there is clear indication that additional broadband noise - on the order of $4 \mathrm{~dB}$ - is removed by the modified stator sets.

Figures 18 and 19 show, respectively, the directivity effects on the 2 and 3BPF fan overtones. SPL reductions in the tone and broadband levels are plotted against the sideline emission angle. Positive noise levels represent noise reductions relative to what was observed for the baseline configuration with the radial stator in the upstream position. Tone reductions for the $2 \mathrm{BPF}$ tone (Fig. 18) are greatest at aft angles, showing $12 \mathrm{~dB}$ reduction associated with moving the radial stator to the downstream location. Noise reductions of 15 and $19 \mathrm{~dB}$ were associated, respectively, with the swept only, and swept + leaned stator.

There were also broadhand noise reductions associated with the swept + leaned, and swept only stators, showing up to $4 \mathrm{~dB}$ broadband noise reduction. Moving the radial stator to the downstream location produced little to no reduction in broadband noise. This result is consistent with that reported in the stator spacing study of Ref. 2 , which likewise noted little change in broadband noise level with (radial) stator spacing.

There has been some concern regarding the periodic nature of the tonal directivity data taken in the $9 \times 15 \mathrm{LSWT}$. While it is possible that this behavior arises from tunnel wall reflections, it is much more likely that the data accurately shows a real interference pattern between aft and forward radiated noise at a particular frequency. There are several observations to support the second interpretation. The fan is aft dominated, therefore one would expect the cancellation pattern to be more pronounced toward the forward angles where the relative noise levels are more nearly equal in level. This is, in fact, what is observed in the sideline data. An analytical study of predicted sideline noise levels was performed which considered a case for inlet and exhaust radiation for an aft dominated fan. Again, a similar noise interference pattern was observed for these analytical resutts. Finally, results for another advanced fan model which was tested in a large anechoic free jet facility showed similar interference in the sideline results-in this case there was no nearby tunnel wall to provide possible reflections. This phenomenon will be further explored in a later section of this report in which an acoustic barrier wall was placed adjacent to the fan model and effectively blocked aftradiated noise from reaching the sideline microphone.

The 3BPF results of Fig. 19 show significant tone reductions, which are now greatest toward the forward angles. Different tone orders are associated with different radiation mode structure, and therefore changes in the directivity patterns are expected. In particular, acoustic interaction modes which are just above cut-off tend to be more forward radiating than more highly cut-on orders. Tone reductions associated with simply moving the radial stator downstream are nearly as great as those associated with the swept + leaned stator (up to $18 \mathrm{~dB}$ ). The swept only stator was slightly less effective for tone removal at forward radiation angles, but essentially equivalent to the swept + leaned stator at the aft angles. The swept + leaned stator was most effective in reducing broadband noise levels at all measured sideline angles.

Figures 20 to 22 present corresponding acoustic results for the fan operating at 84 percent design speed. The spectral overlay of Fig. 20 is similar to the 50 percent speed results of Fig. 17 in that the fundamental tone Is essentially cut-off, and most overtone energy is associated with the radial stator in the upstream position. The "haystacking" nature of the swept + leaned spectra near 3BPF may be associated with flow disturbances caused by the poorer aerodynamic performance of that stator.

Figure 21 shows sideline noise reductions for the $2 \mathrm{BPF}$ tone and broadband. The two modified stators were essentially equivalent in terms of tonal noise reduction. Tone reductions associated with the radial stator in the downstream position were almost as good as those for the modified stators except for downstream sideline angles beyond $100^{\circ}$. Broadband noise reductions for the modified stators were about $2 \mathrm{~dB}$ at upstream angles, increasing to 4 to $5 \mathrm{~dB}$ at further aft angles.

Tone reductions at 3BPF and 84 percent design speed (Fig. 22) showed similar reductions for the modified and further downstream radial stators. Broadband noise reductions at 3BPF were greatest with the swept only stator. The swept + leaned stator generated increased broadband noise at sideline angles from 90 to $110^{\circ}$.

The fundamental rotor-stator interaction tone remained cut-off at 100 percent design speed (Fig. 23). However, higher-order tones are now present in the spectra for the radial stator in the downstream position and for the swept and leaned stator. Data were not taken at this speed for the swept only stator due to aeromechanical avoidance zones for this stator and fan speed. There is essentially no interaction tone for the swept + leaned stator until 4BPF (and higher) harmonics.

Fundamental (BPF) tone and broadband reductions as a function of emission angle are shown in Fig. 24 . The interesting observation here is that, although cut-off, there is a significant noise increase associated with the swept + leaned stator. Again, the suspect cause is the lesser aerodynamic performance of that stator.

The swept + leaned stator had much more effect than the radial stator in the downstream position in reducing 
2BPF tone noise at 100 percent fan speed (Fig. 25). However there was essentially no broadband reduction at 2BPF. A similar result was observed at 3BPF (Fig. 26).

All stator configurations produced significant tone noise at the 110 percent overspeed condition. The fundamental rotor-stator interaction tone is now weakly cut-on and is evident for the radial stator at the two axial locations and for the swept only stator. However, this tone is not evident for the swept + leaned stator (Fig. 27). The swept + leaned stator essentially eliminated the 2 and 3BPF tones from the spectra. The swept only stator was marginally effective in reducing acoustic energy at these tone orders.

The fundamental tone directivity results of Fig. 28 likewise shows significant noise reductions associated with the swept + leaned stator, with somewhat increased noise levels (relative to the radial stator in the forward position) seen for the swept only and radial stator in the downstream position. The broadband levels at BPF were essentially unchanged by stator configuration, except for small reductions at upstream angles with the swept + leaned stator. A corresponding noise increase was associated with the downstream radial stator at these forward angles.

The directivity results at 2 and $3 B P F$ (Figs. 29 and 30) were somewhat similar, showing that the swept + leaned stator was most effective in reducing tone and broadband energy at this fan speed.

These results for the constant bandwidth tone and broadband directivities are consistent with those presented earlier in this report for the fictitious aircraft effective perceived noise levels (Figs. 12 to 15 ). Stators correctly redesigned with sweep + lean, or possibly sweep only have been shown to significantly reduce both rotor-stator interaction tone and broadband noise levels. However, there is not a consistent story as to whether sweep + lean or sweep only is the preferred modification. The relative stator performance varied with fan speed. This story is further complicated by the observation that the swept + leaned stator showed greater aerodynamic losses than did the other stators, suggesting that its acoustic performance, likewise, was compromised. On the other hand, one could infer that the expected acoustic benefits of a better designed swept + leaned stator would be at least as good as were shown herein, and perhaps better.

Data repeatability. The modified stator sets showed significant reductions in fan tone levels, therefore there is a need to validate the repeatability of these results. Repeat data runs for two stator configurations were made to quantify repeatability of the acoustic data. In each instance, the second set of data represents a fan rebuild and was acquired at a totally different test time. Thus, the following comparisons are rather rigorous toward validating the acoustic data. Successive data were taken for the swept + leaned stator and for the radial stator in the downstream axial position.

Sideline 1/3 octave directivities comparing repeat data sets are shown in Figs. 31 and 32, respectively, for the 2500 and $20000 \mathrm{~Hz}$ frequency band. In each instance the data repeatability is excellent.

Acoustic barrier wall. Noise levels for modern highbypass ratio subsonic turbofans tend to be aft-dominated. That is, the highest flyover noise levels radiate from the fan exit. Measurement of fan inlet sound radiation without aft radiation contamination requires selective suppression of the aft noise. An acoustic barrier was used in the NASA Lewis $9 \times 15$ LSWT to effectively isolate the inlet noise field from the fan exit noise. The acoustic barrier was mounted on tracks on the tunnel floor and ceiling at a sideline distance of $15 \mathrm{~cm}(6 \mathrm{in}$.) from the fan nacelle. Tests were made with the wall leading edge at the fan inlet highlight plane and $15 \mathrm{~cm}(6 \mathrm{in}$.) further aft. The wall extended downstream essentially to the end of the treated tunncl test section. The barrier was constructed in sections which were joined upon installation. The barrier was of wood frame construction, $8 \mathrm{~cm}(3 \mathrm{in}$.) thick, with typically $0.64 \mathrm{~cm}(0.25 \mathrm{in}$.) tempered fiberboard skins. An elliptical leading edge was faired into the upstream barrier section. The barrier sections extended floor to ceiling and had an axial length of $61 \mathrm{~cm}(24 \mathrm{in}$.). The upstream section had nominal full height by $46 \mathrm{~cm}$ ( $18 \mathrm{in}$.) axial length acoustic treatment on the fan side of the barrier just downstream of the leading edge. This treatment consisted of a bulk absorber with a perforated metal skin. Inlet airflow computations indicated that the presence of the barrier wall should have a minimal effect on fan aerodynamic performance. The barrier wall was shown to structurally sound up to 0.20 Mach tunnel velocity.

Figure 33 is a photograph of the Allison fan in the NASA Lewis $9 \times 15$ tunnel showing the acoustic barrier in the upstream position. The sideline translating microphone probe may be seen in the background. Figure 34 is a sketch of the acoustic barrier wall installed in the $9 \times 15$ LSWT.

Figures 35 to 38 show $1 / 3$ octave directivities for the baseline fan with the radial stator in the upstream position, and with the acoustic barrier wall installed at the two axial locations (leading edge at fan inlet highlight and $15 \mathrm{~cm}$ (6 in.) further aft). Figures 35 and 36 show $1 / 3$ octave directivities for the fan operating at 50 percent design speed. Figure 35 shows representative broadband results at $2500 \mathrm{~Hz}$. The presence of the barrier wall significantly reduced fan aft noise levels, with somewhat better aft suppression with the wall leading edge located at the fan inlet highlight. Similar results are seen in Fig. 36 for the 3BPF tone. Maximum wall shielding at this fan speed is about $20 \mathrm{~dB}$. It is interesting to note that acoustic modal structure from (presumably) inlet radiation is now exposed due to the harrier wall shielding. 
Figures 37 and 38 show corresponding directivity results for the fan operating at 100 percent design speed. The barrier wall at both axial locations significantly reduced aft-radiated broadband noise (Fig. 37). Likewise, the wall was quite effective in shielding aft-radiated $4 \mathrm{BPF}$ tone noise. Maximum shielding of this strong tone (Fig. 23) was about $25 \mathrm{~dB}$.

Figures 39 to 43 show the effect of the barrier wall on the fan acoustic power. Figure 39 shows the overall sound power level (OAPWL) calculated with $1 / 3$ octave data from 2000 to $20000 \mathrm{~Hz}$. The data are for the translating microphone probe for emission angles from $2510130^{\circ}$. The presence of the barrier wall reduced the OAPWL from about $4 \mathrm{~dB}$ at the lower fan speeds to over $10 \mathrm{~dB}$ at the higher speeds. The fan noise directivity becomes increasingly aft-dominated at higher speeds where the barrier wall is shown to significantly reduce the measured sound power. As expected, the barrier wall is slightly more effective at its upstream location with the wall leading edge at the fan inlet highlight.

Figures 40 and 41 show the corresponding fan OAPWL for forward emission angles $\left(25\right.$ to $\left.61^{\circ}\right)$ and downstream angles $\left(61\right.$ to $\left.130^{\circ}\right)$, respectively. The upstream OAPWL results of Fig. 40 show essentially no barrier wall effect at fan speeds below 85 percent design, where the fan noise directivity begins to become more aft dominated. There is some wall-induced noise reduction at higher fan speeds, showing that dominant aft-radiated fan noise is present at these upstream angles. There was essentially no difference in barrier wall effectiveness for the two wall axial positions.

The barrier wall was quite effective in reducing the downstream OAPWL (Fig. 41), with reductions typically about $10 \mathrm{~dB}$ at lower fan speeds, increasing to $15 \mathrm{~dB}$ at the higher speeds. The aft noise levels were sensitive to wall location, being about $1.5 \mathrm{~dB}$ lower with the wall at the forward axial location at the inlet highlight. However, the wall axial location had no effect on noise reduction at 100 and 105 percent fan design speed where the noise is highly aft-dominant.

The fan first overtone (2BPF) was cuton at all fan speeds. Figure 42 shows the sound power levels (PWL) for the $1 / 3$ octave band containing this $2 \mathrm{BPF}$ tone as a function of fan speed. Again, the data are for the translating microphone probe over an emission angle range from 25 to $130^{\circ}$. These results are very similar to those seen for the OAPWL in Fig. 39. Figure 43 shows the tone PWL derived from $59 \mathrm{~Hz}$ narrowband data. The use of this finer bandwidth facilitates better separation of the 2BPF tone from other noise, such as broadband. These results are similar to the $1 / 3$ octave tone results of Fig. 42 , although the actual noise reductions due to the wall are somewhat higher, being 15 or more $\mathrm{dB}$ at the highest fan speeds.

These acoustic results show that the barrier wall can be a useful tool for isolating inlet radiation from an aft- dominated fan in the LeRC $9 \times 15$ LSWT. This technique should have application for investigating inlet acoustic treatment effects or wherever it is desirable to eliminate aft noise from the acoustic signature in the $9 \times 15$ anechoic wind tunnel.

\section{Concluding Remarks}

An advanced high bypass ratio fan model was tested in the NASA Lewis 9- by 15-Foot Low Speed Wind Tunnel. The primary focus of this test was to quantify the acoustic benefits and aerodynamic performance of sweep and lean in stator vane design. Three stator sets were used for this test series. A conventional radial stator was tested at two rotor-stator axial spacings-a relatively close spacing and a more open spacing, axially downstream. Additional stator sets incorporating sweep + lean, and sweep only were also tested. The hub and tip axial locations for the swept+ leaned, and swept only stators corresponded to the hub and tip locations of the radial stators at the two axial spacings. In theory, the use of about $30^{\circ}$ of sweep and lean should significantly reduce the impact of rotor wake-stator interaction, thus resulting in lower rotor-stator noise levels.

The results clearly showed that incorporation of stator sweep + lean, or sweep only can significantly reduce rotor-stator tone levels. Tone levels for the modified stators were significantly reduced beyond what was achieved by simply relocating the conventional radial stator to the downstream location. It is not clear if stator sweep alone is typically adequate to achieve substantial reductions in rotor-stator interaction noise, or if there are significant additional benefits to be realized through incorporation of both sweep + lean. In particular, the aerodynamic performance of the swept + leaned stator showed somewhat higher losses than that of the other stators, suggesting that noise reductions associated with this stator may be further improved through enhanced aerodynamic design of a swept + leaned stator.

There is increasing interest in reducing broadband noise levels of advanced subsonic turbofans. Noise signatures of modern turbofan engines are increasingly dominated by broadband noise rather than rotor-stator tone noise. Increased axial spacing of a conventional radial stator does not impact the fan broadband noise level, except, perhaps, to increase the potential for broadhand noise generation through increased scrubbing surface, etc. However, the results for the swept + leaned, and swept only stators reported herein did show a significant reduction (often on the order of $4 \mathrm{~dB}$ ) of the broadband noise relative to that generated with the radial stator.

Acoustic results scaled to a fictitious 2-engine aircraft and flight path suggested that about 3 EPNdB could be realized through incorporation of these modified stators a result which could represent a significant part of the 
current AST initiative goal of a 6 EPNdB reduction relative to 1992 technology levels.

These results suggest that incorporation of some combination of stator sweep and lean may significantly reduce both tone and broadband noise levels for future advanced turbofans. Additional research in this area should further quantify the aeroacoustic performance of these modified stators and give insights into methodology for additional engine noise reduction.

\section{REFERENCES}

1. Tyler, J.M. and Sofrin, T.G., "Axial Flow Compressor Noise Studies," SAE Trans., Vol. 70, 1962, pp. 309-332.

2. Woodward, R.P., and Glaser, F.W., "Wind Tunnel Measurements of Blade/Vane Ratio and Spacing Effects on Fan Noise," AIAA Journal of Aircraft, Vol. 20, No. 1, January, 1983, pp. 58-65.

3. Kazin, S. B., "Radially Leaned Outlet Guide Vanes for Fan Source Noise Reduction," NASA CR-134486, November, 1973.

4. Envia, E., Huff, D.L. and Morrison, C.R., "Analytical Assessment of Stator Sweep and Lean in Reducing
Rotor-Stator Tone Noise," AIAA 96-1791, May, 1996.

5. Dahl, Milo D., and Woodward, Richard P., "Comparison Between Design and Installed Acoustic Characteristics of the NASA Lewis 9- by 15-Foot Low Speed Wind Tunnel Acoustic Treatment," NASA TP-2996, April, 1990.

6. Dahl, Milo D., and Woodward, RichardP.,"Acoustical Evaluation of the NASA Lewis 9-by 15-Foot Low Speed Wind Tunnel," NASA TP-3274, November, 1992.

7. Woodward, Richard P., and Dittmar, James H., "Background Noise Levels Measured in The NASA Lewis 9- by 15-Foot Low-Speed Wind Tunnel, "NASA TM-106817, AIAA-95-0720, January, 1995.

8. Dalton, W.N., Elliott, D. B., and Nickols, K.L., "Design of a Low Speed Fan Stage for Noise Suppression," Allison Engine Company, Allison EDR 17923, NASA CR-“TBD”, June, 1997.

9. Chestnutt, D., "Flight Effects of Fan Noise," NASA CP-2242, January, 1982.

TABLE I.-ALLISON FAN DESIGN CHARACTERISTICS

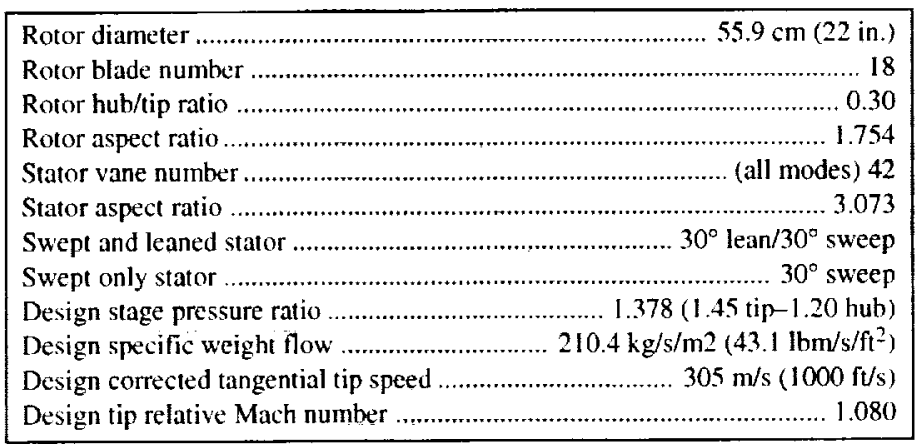




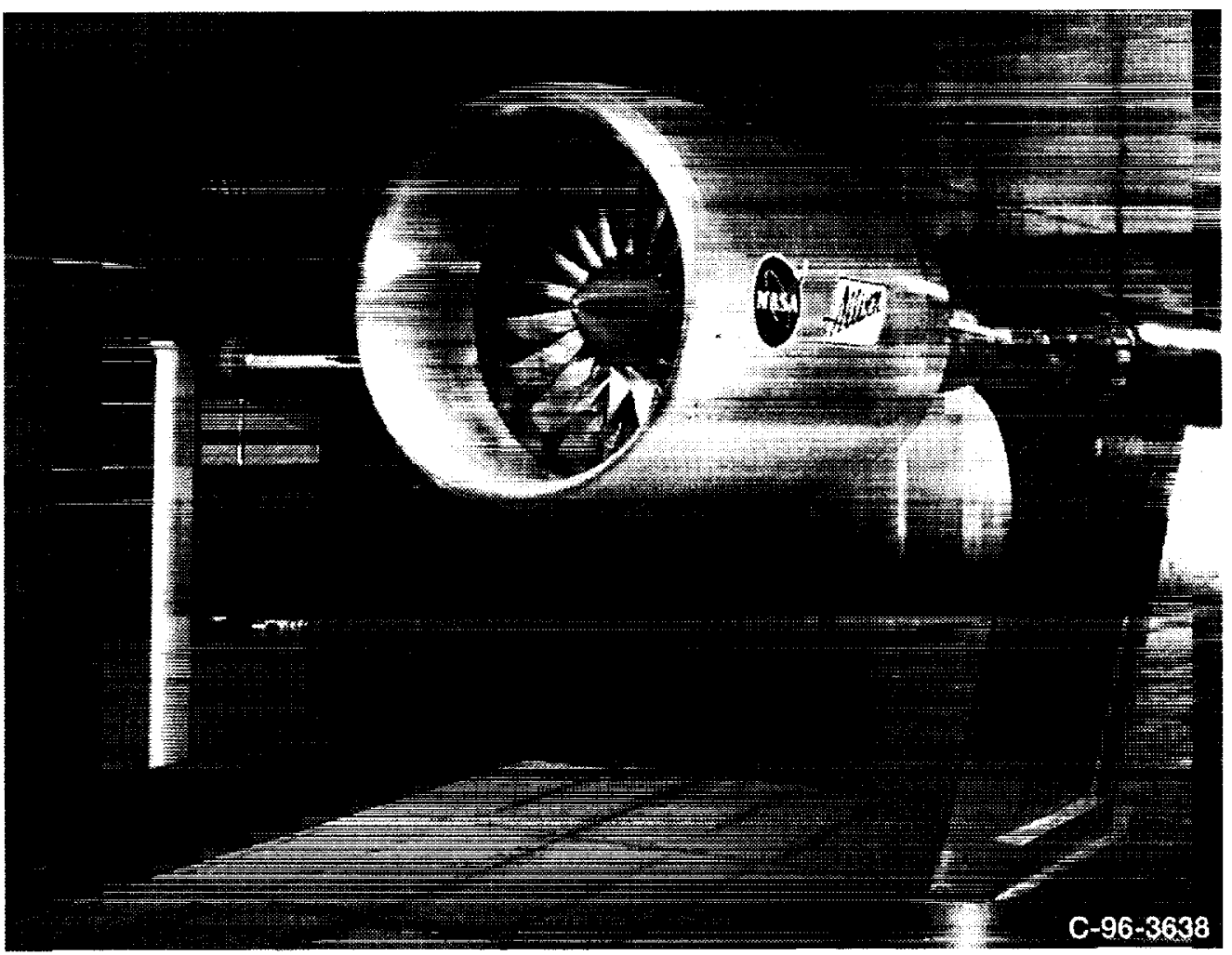

Figure 1.-Photograph of the Allison fan installed in the NASA Lewis $9 \times 15$ LSWT.
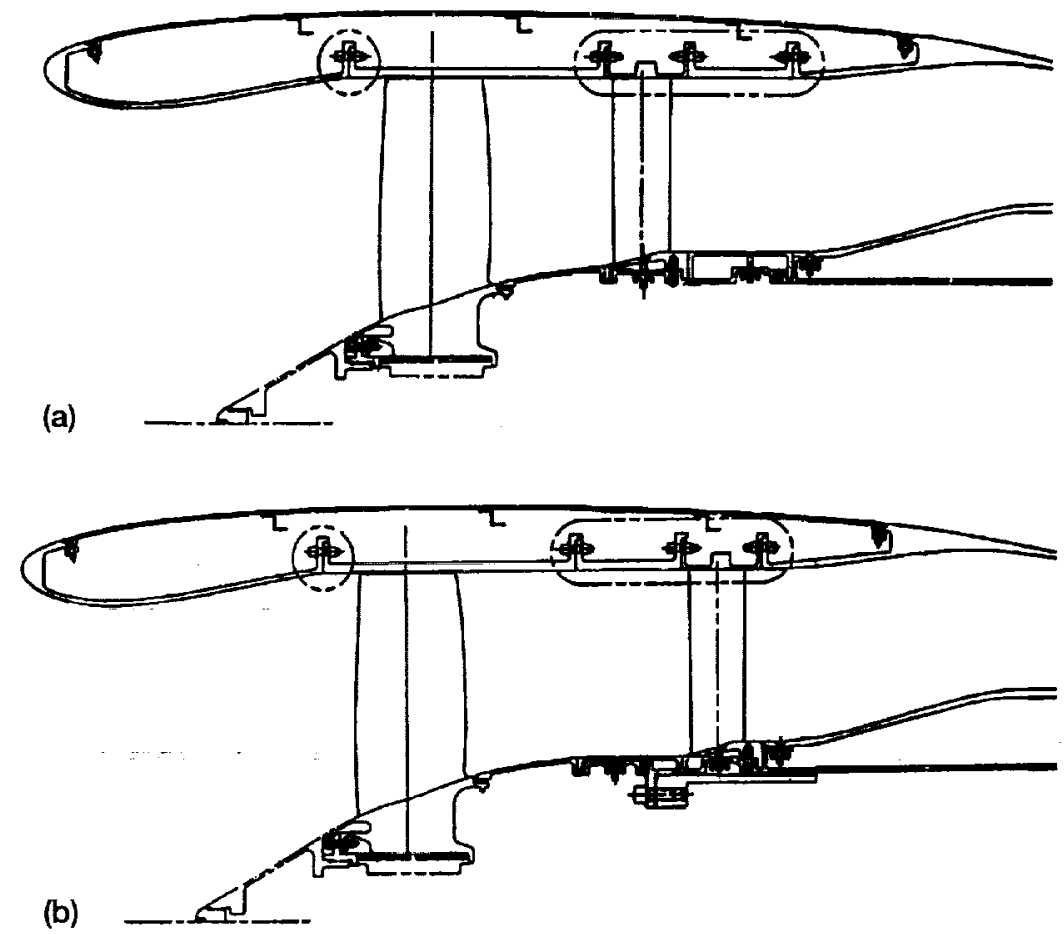

Figure 2.-Sketch of the Allison fan with the baseline radial stator in the forward and aft positions. (a) Upstream position. (b) Downstream position. 

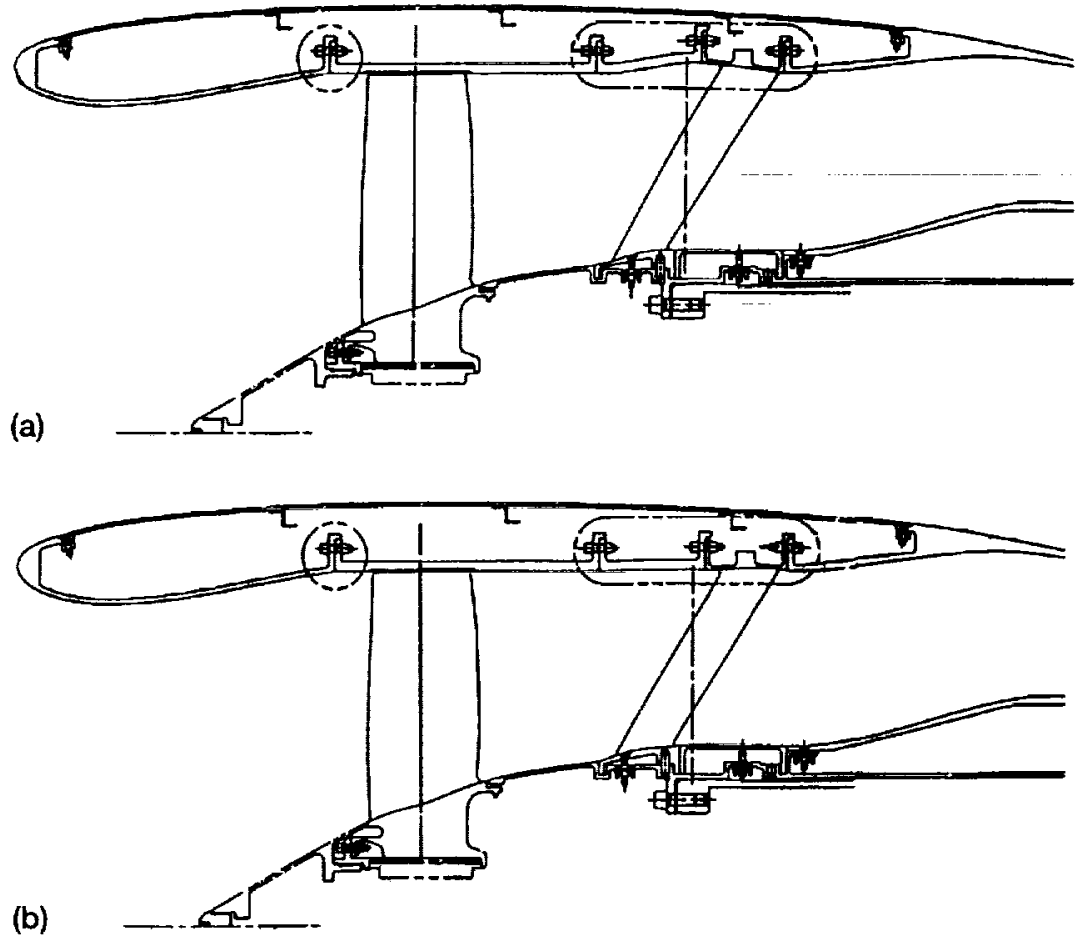

Figure 3.-Sketch of the Allison fan with the swept + leaned and swept only stator. (a) Swept only stator. (b) Swept + leaned stator.

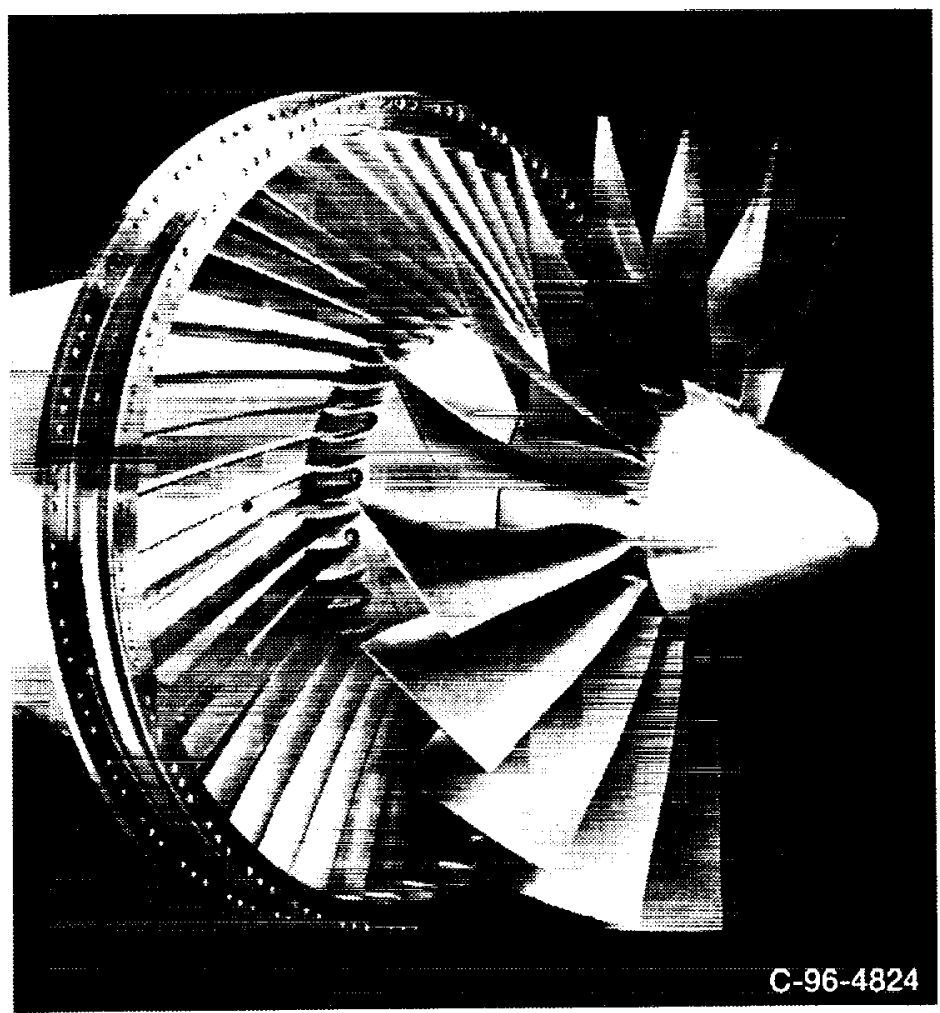

Figure 4.-Photograph of the partially-assembled fan stage showing the swept + leaned stator. 


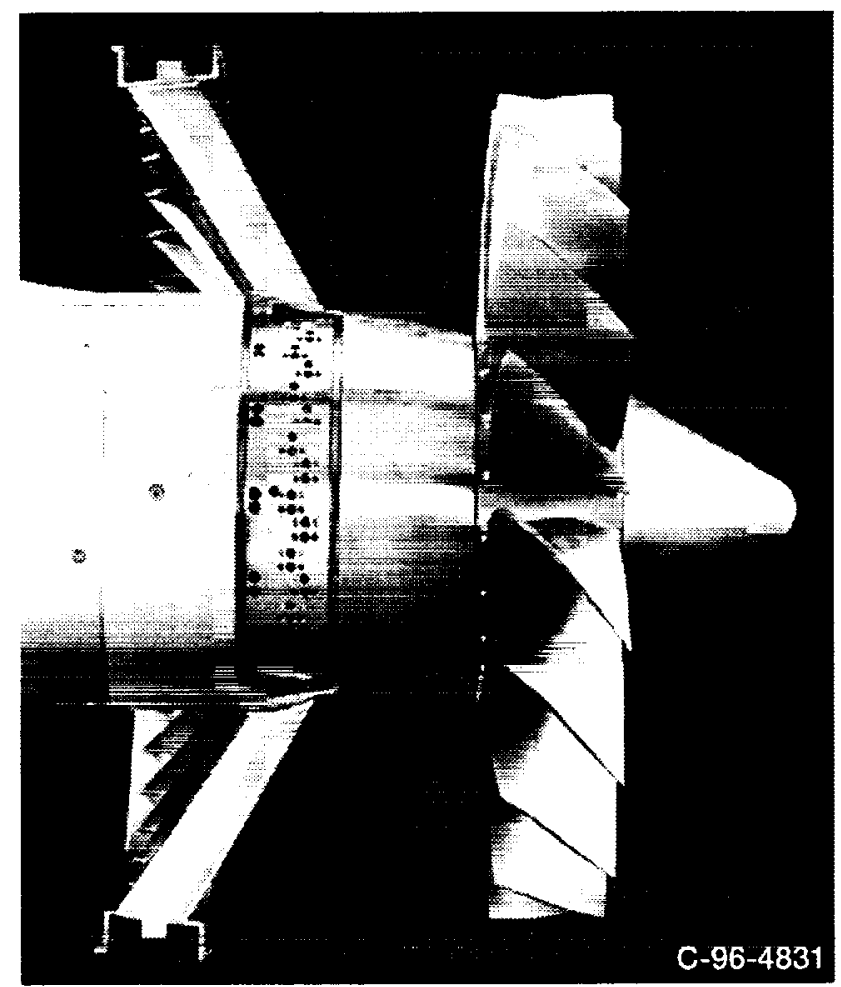

Figure 5.-Photograph of the partially-assembled fan stage showing the swept-only stator.

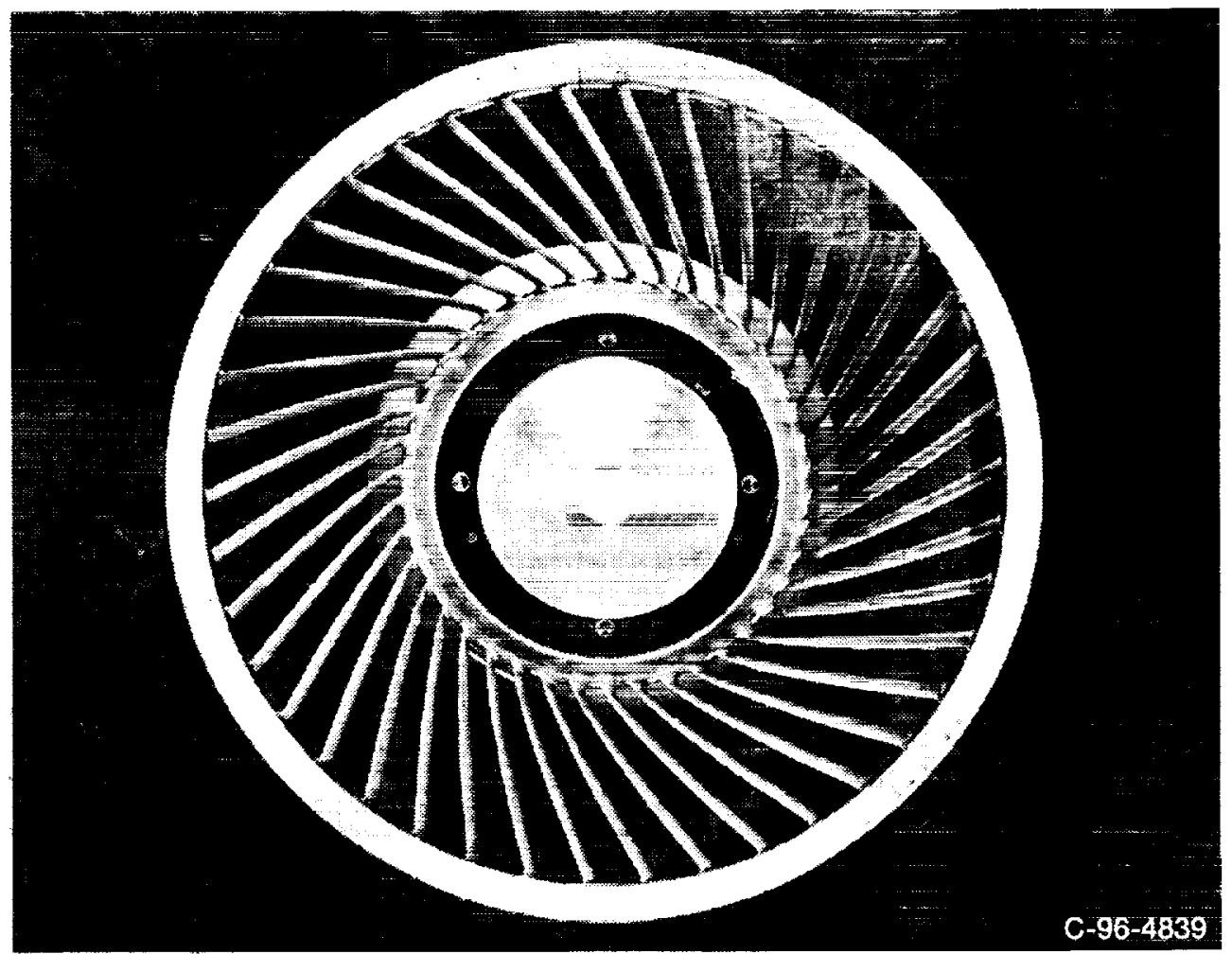

Figure 6.-Downstream view of the swept + leaned stator. 


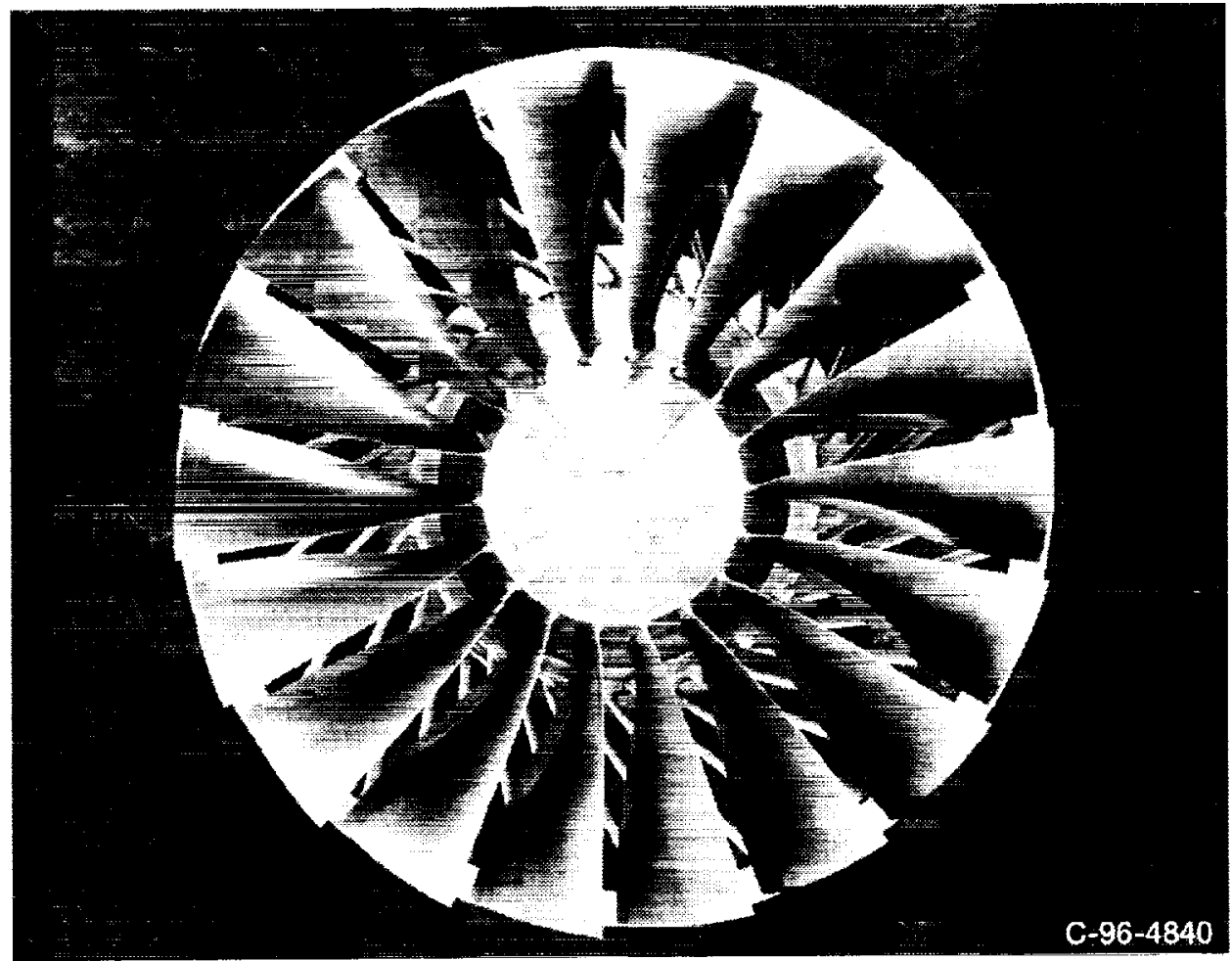

Figure 7.-Downstream view of the swept + leaned stator viewed through the rotor. The fan direction of rotation is counter-clockwise.

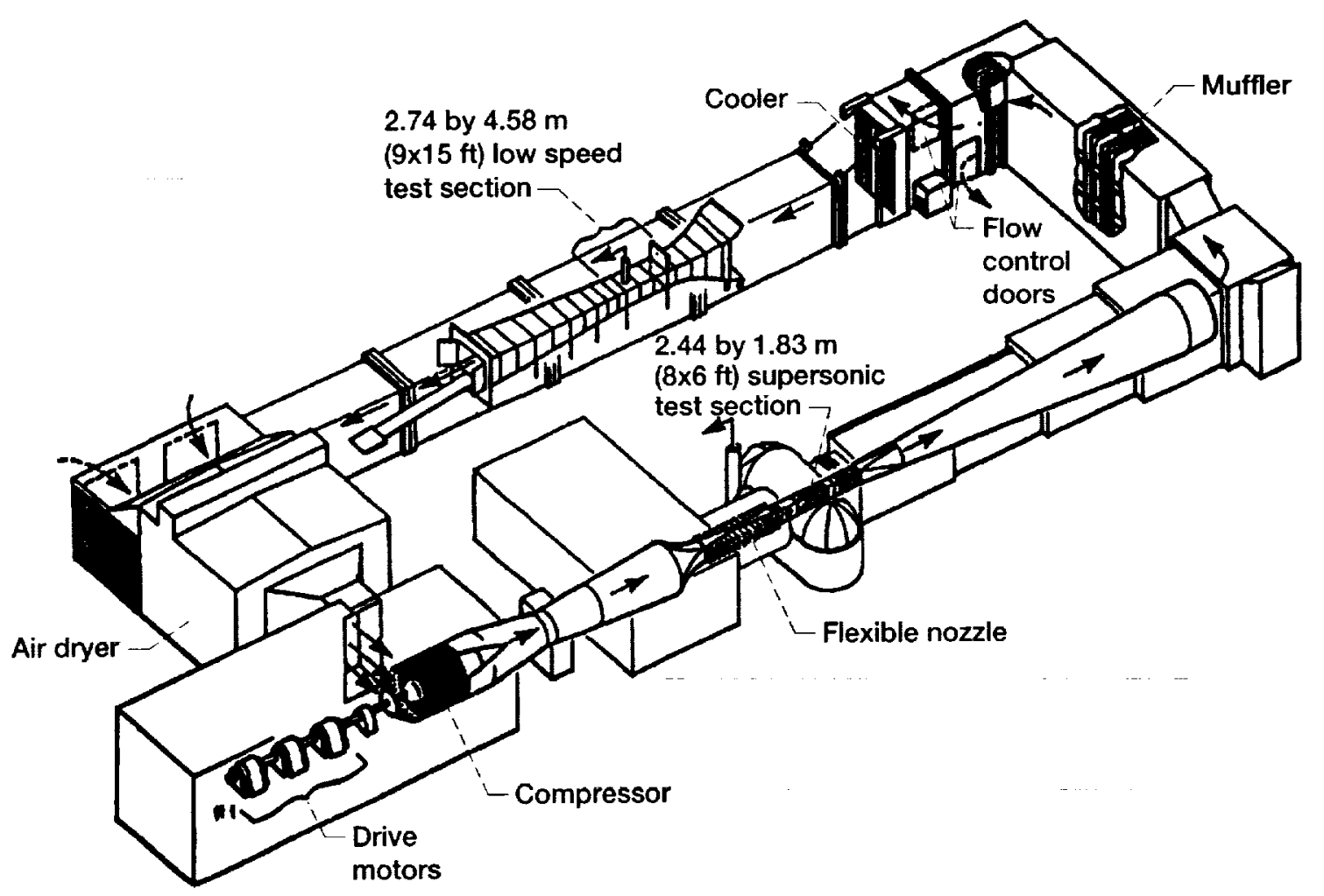

Figure 8.-NASA Lewis $9 \times 15$ Low Speed Anechoic Wind Tunnel. 


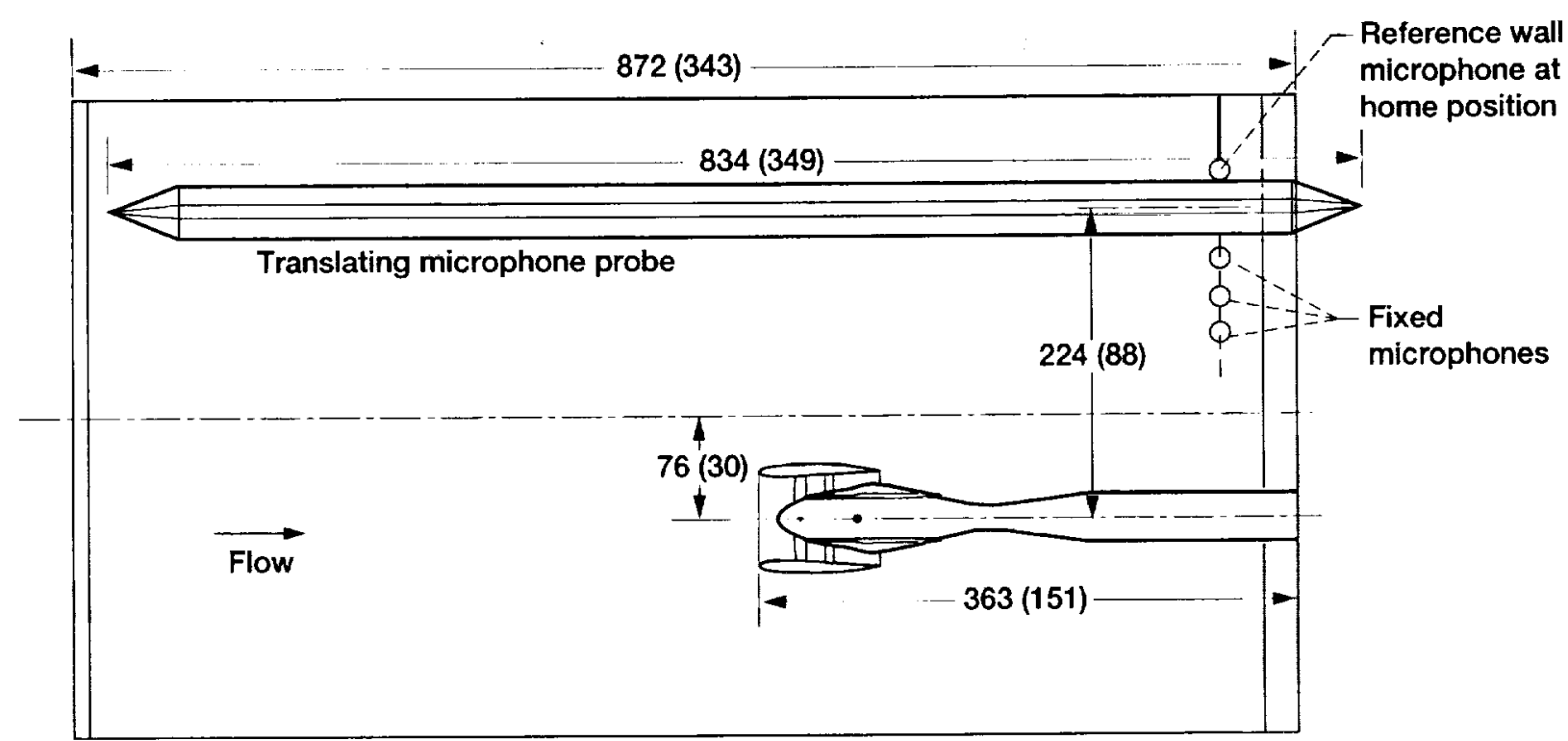

Figure 9.-Sketch of the Allison fan installed in the $9 \times 15$ wind tunnel anechoic test section. (All dimensions are in cm (in.)).

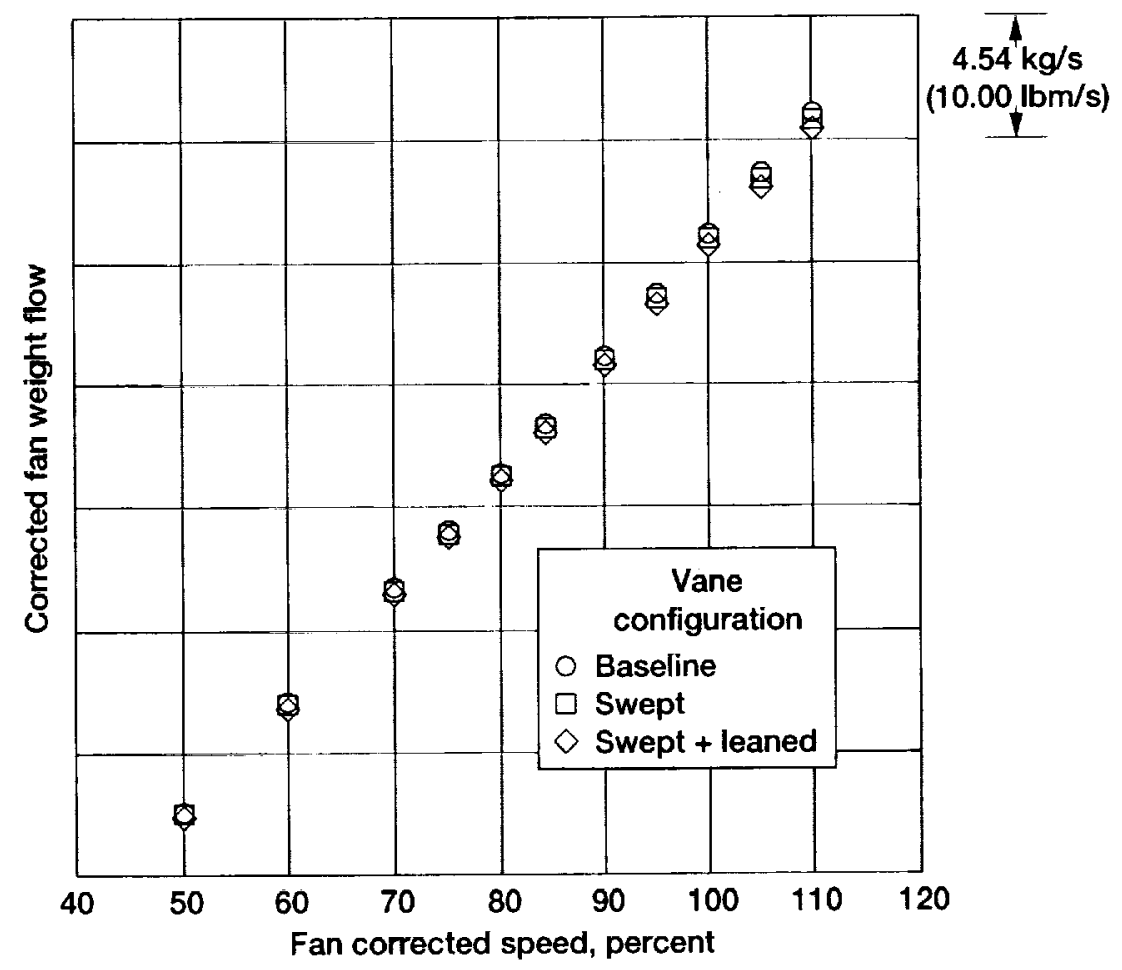

Figure 10.-Fan stage weight flow comparison for the radial (baseline), swept + leaned, and swept only stator. 


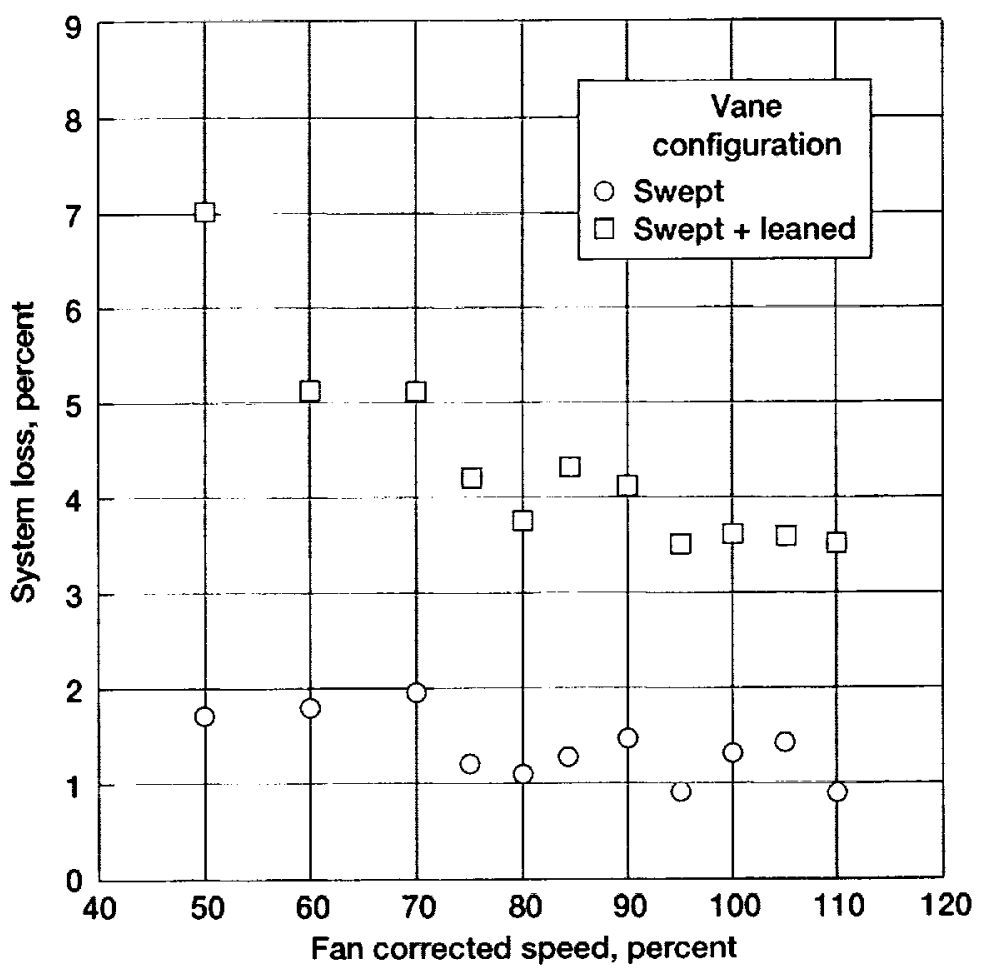

Figure 11.-System thrust loss relative to baseline (radial) stator. (Note: Vanes not optimized for performance - no core flow and sharp corner flows. Swept only vanes partially optimized using area ruling at the tip.)

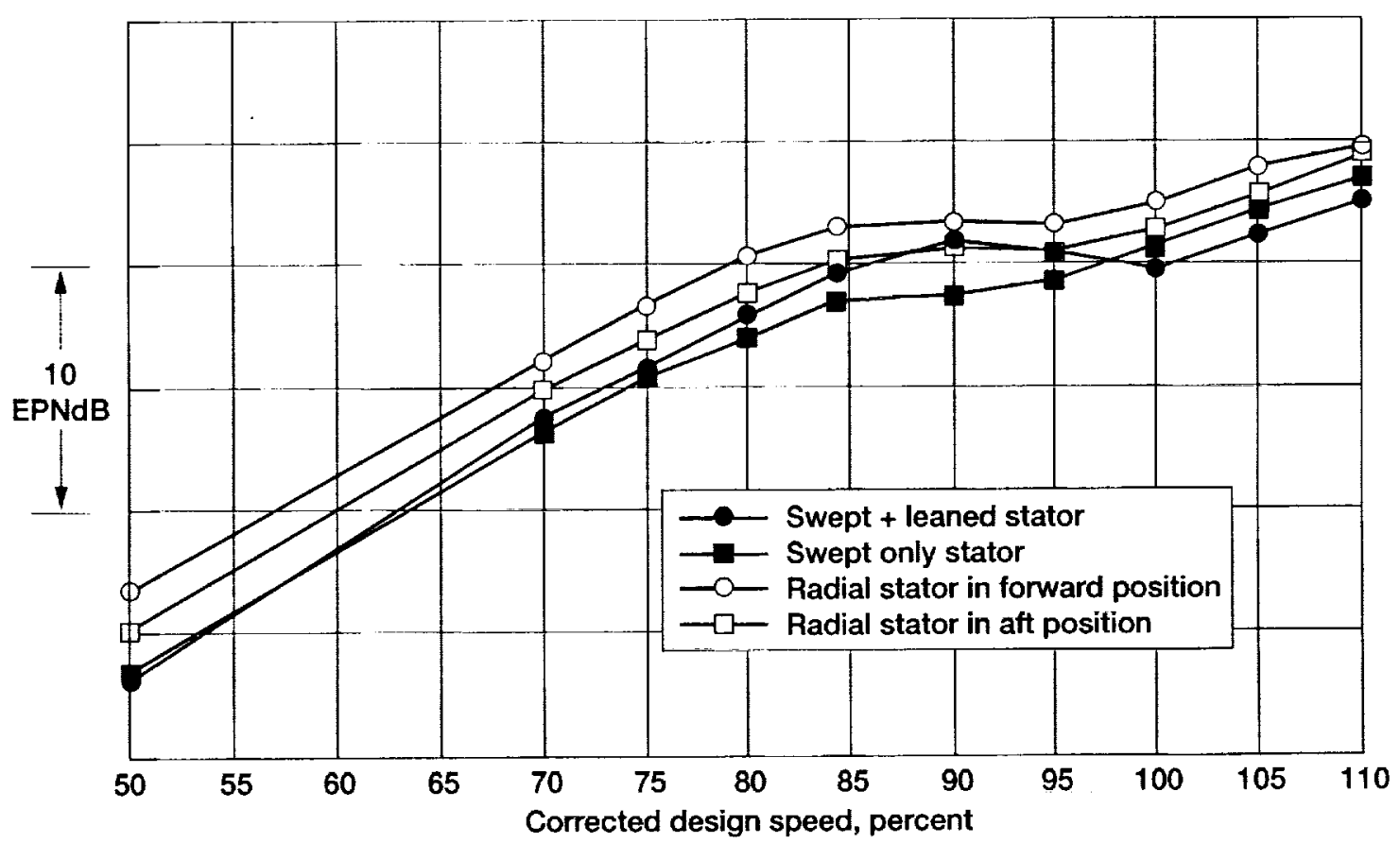

Figure 12.-Sideline EPNL for fictitious 2-engine aircraft and flight path. Maximum noise level for an observer on a $610 \mathrm{~m}(2000 \mathrm{ft})$ sideline. 


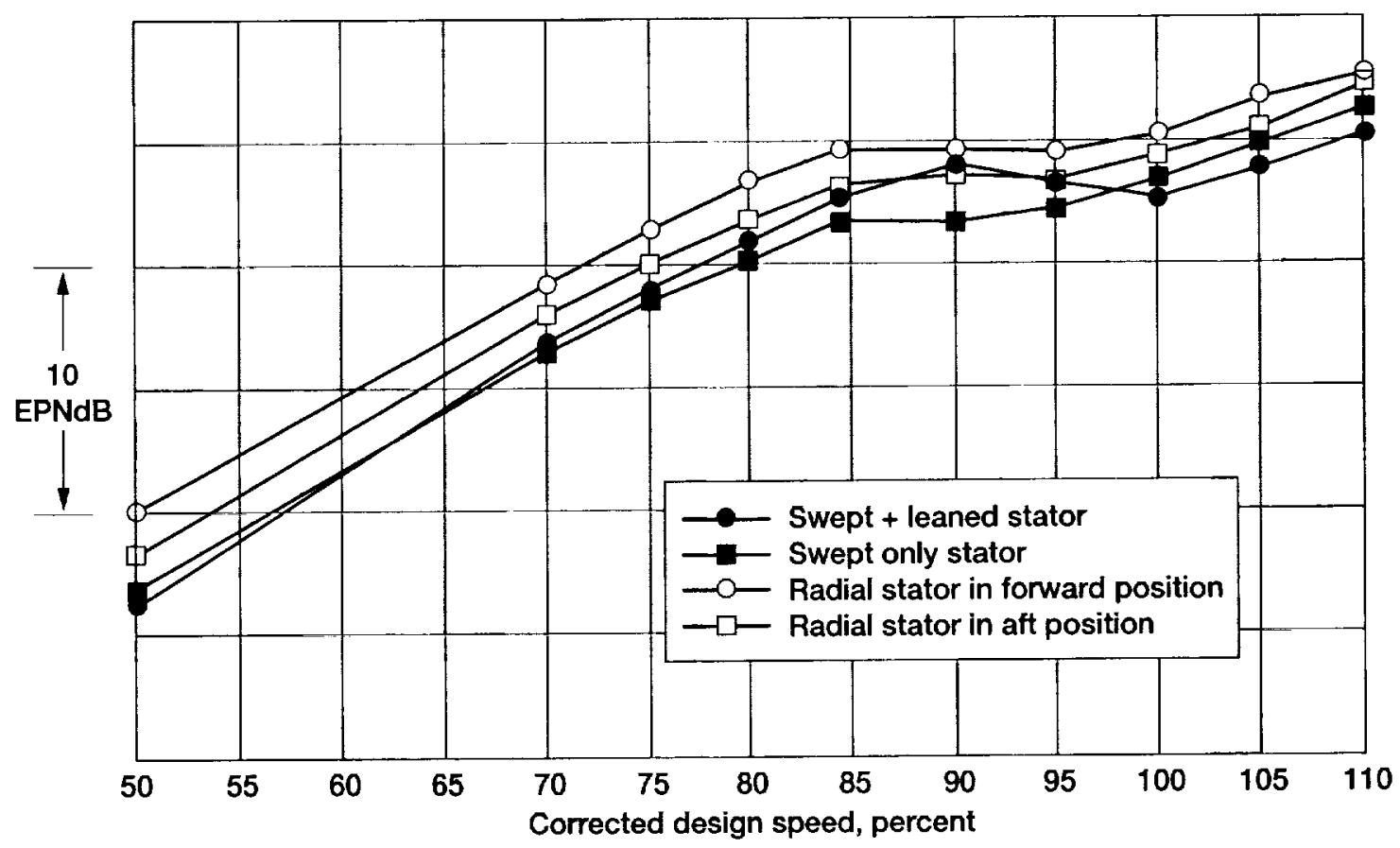

Figure 13.-Flyover EPNL for fictitious 2-engine aircraft and flight path. Maximum noise level for an observer 3.5 nautical miles from brake release in line with runway.

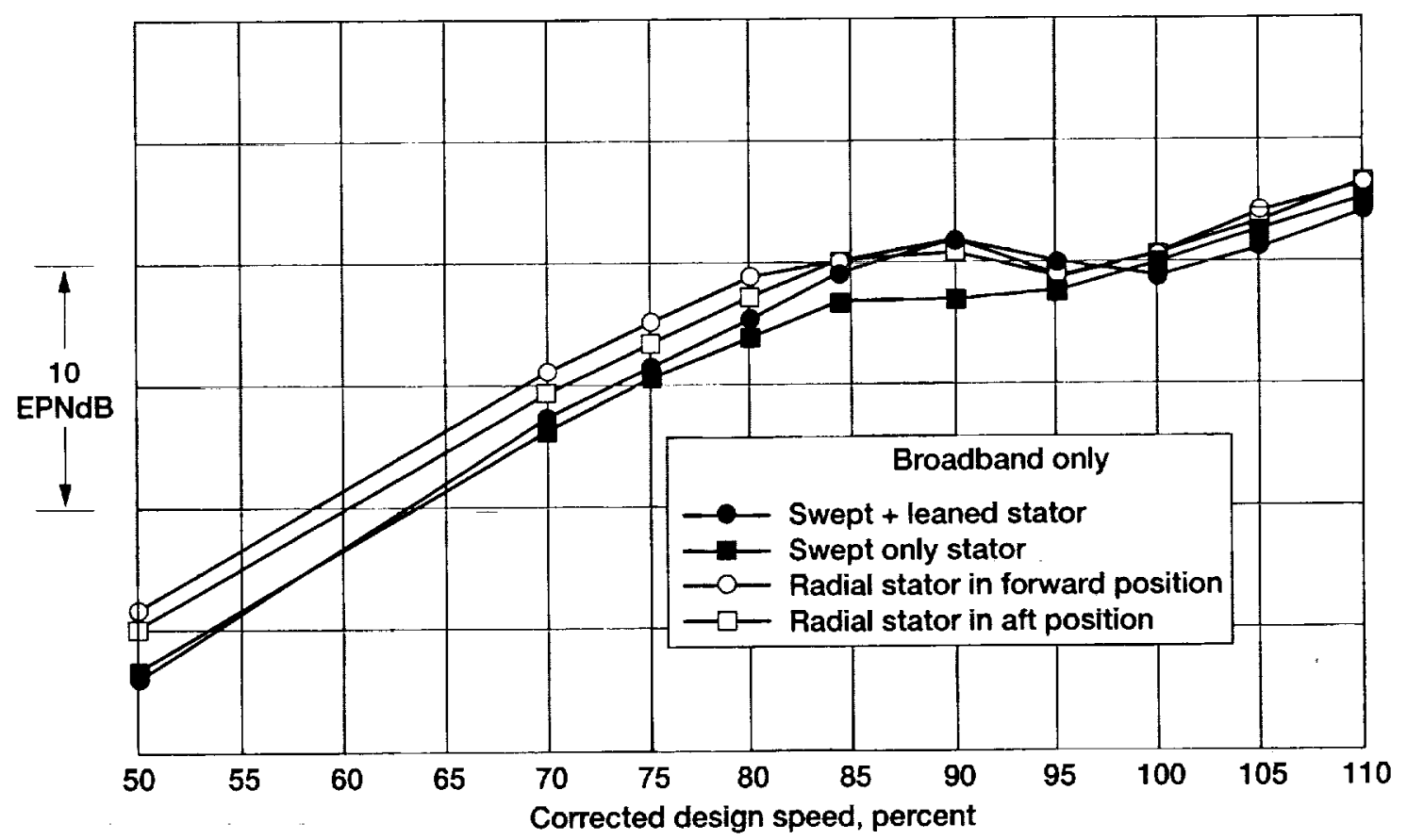

Figure 14.-Sideline broadband EPNL for fictitious 2-engine aircraft and flight path. Maximum noise level for an observer on a $610 \mathrm{~m}(2000 \mathrm{ft})$ sideline. 


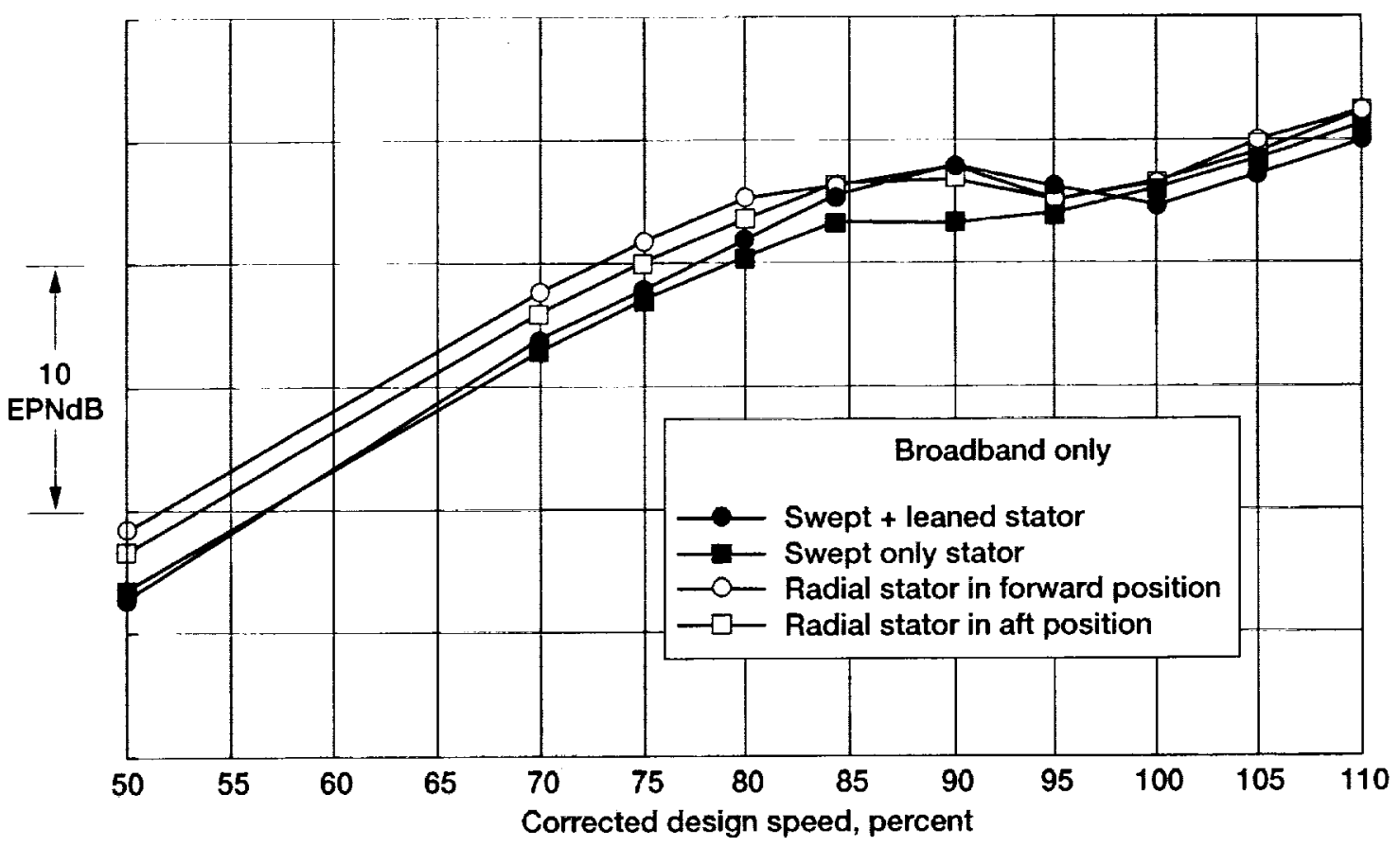

Figure 15.-Flyover broadband EPNL for fictitious 2-engine aircraft and flight path. Maximum noise level for an observer 3.5 nautical miles from brake release in line with runway.

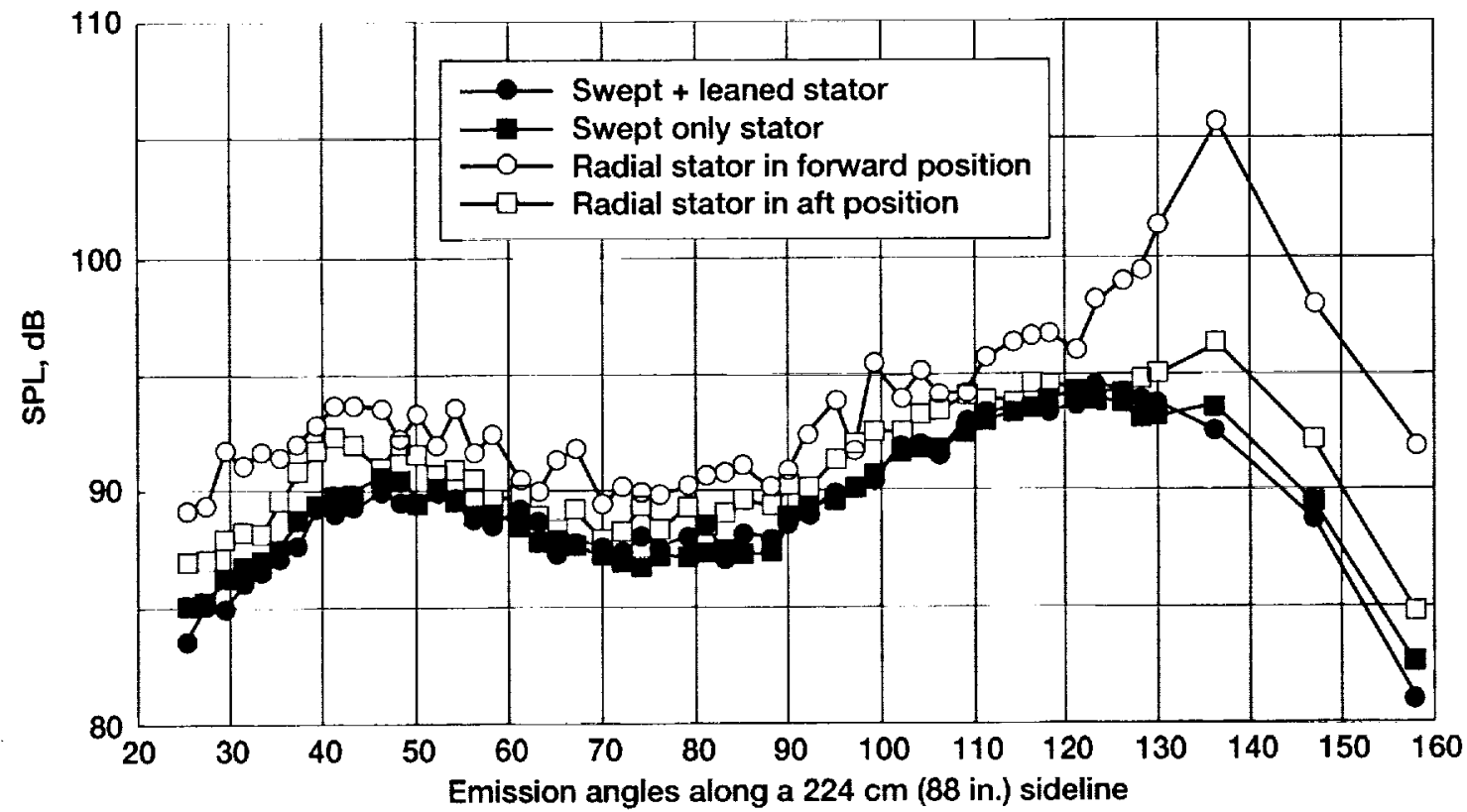

Figure 16. - One-third octave directivities along a $224 \mathrm{~cm}$ ( $88 \mathrm{in}$.) sideline (50 percent fan design speed, 2BPF tone). 


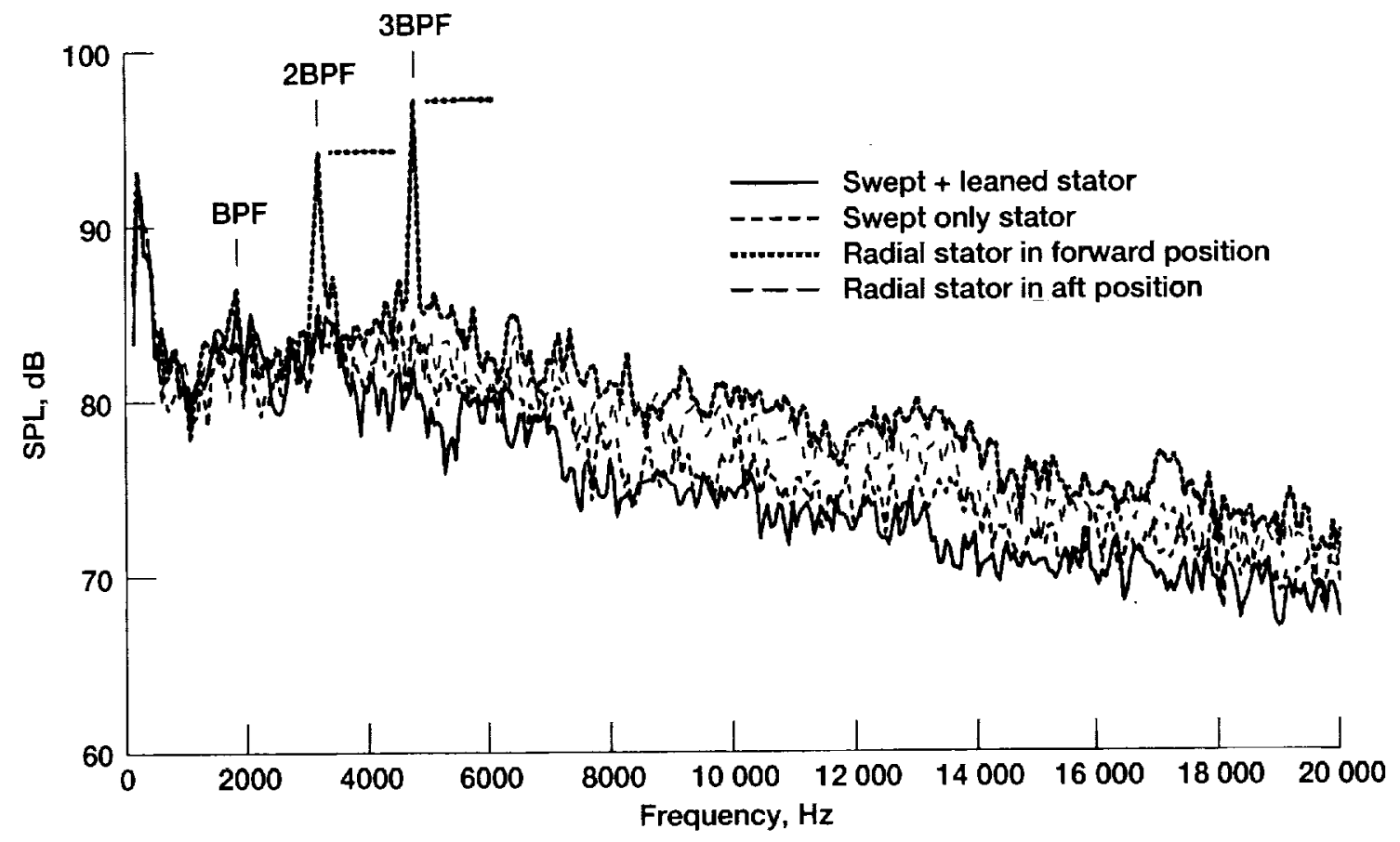

Figure 17. - Constant bandwidth $(59 \mathrm{~Hz})$ spectra on a $224 \mathrm{~cm}\left(88 \mathrm{in.}\right.$.) sideline at $126^{\circ}$ from inlet axis.

Fan is operating at 50 percent design speed.
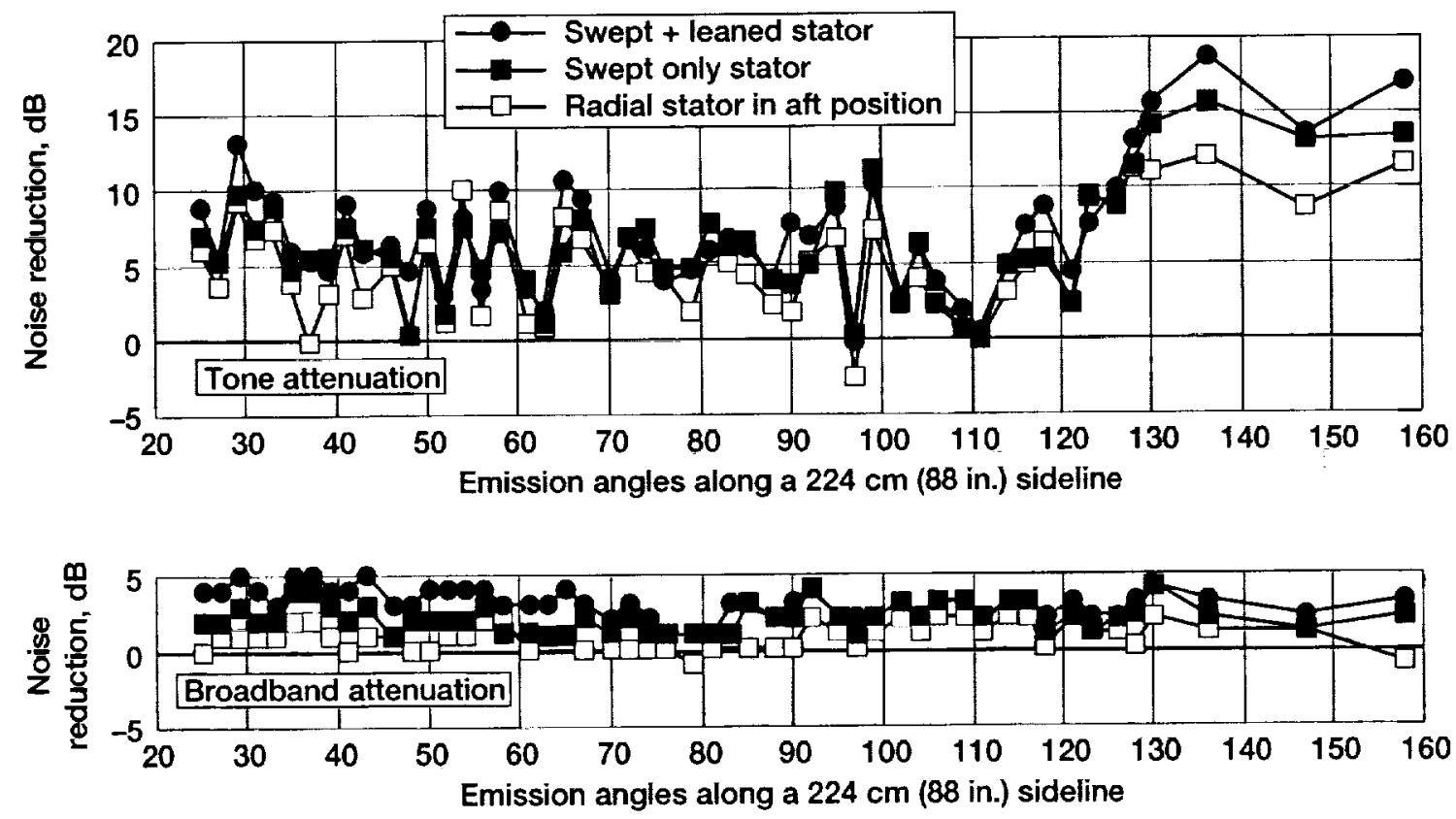

Figure 18.-Sideline constant bandwidth $(59 \mathrm{~Hz})$ directivities showing noise reduction relative to baseline configuration with the radial stator in the forward (upstream) position (50 percent fan design speed, SPL at 2BPF). 

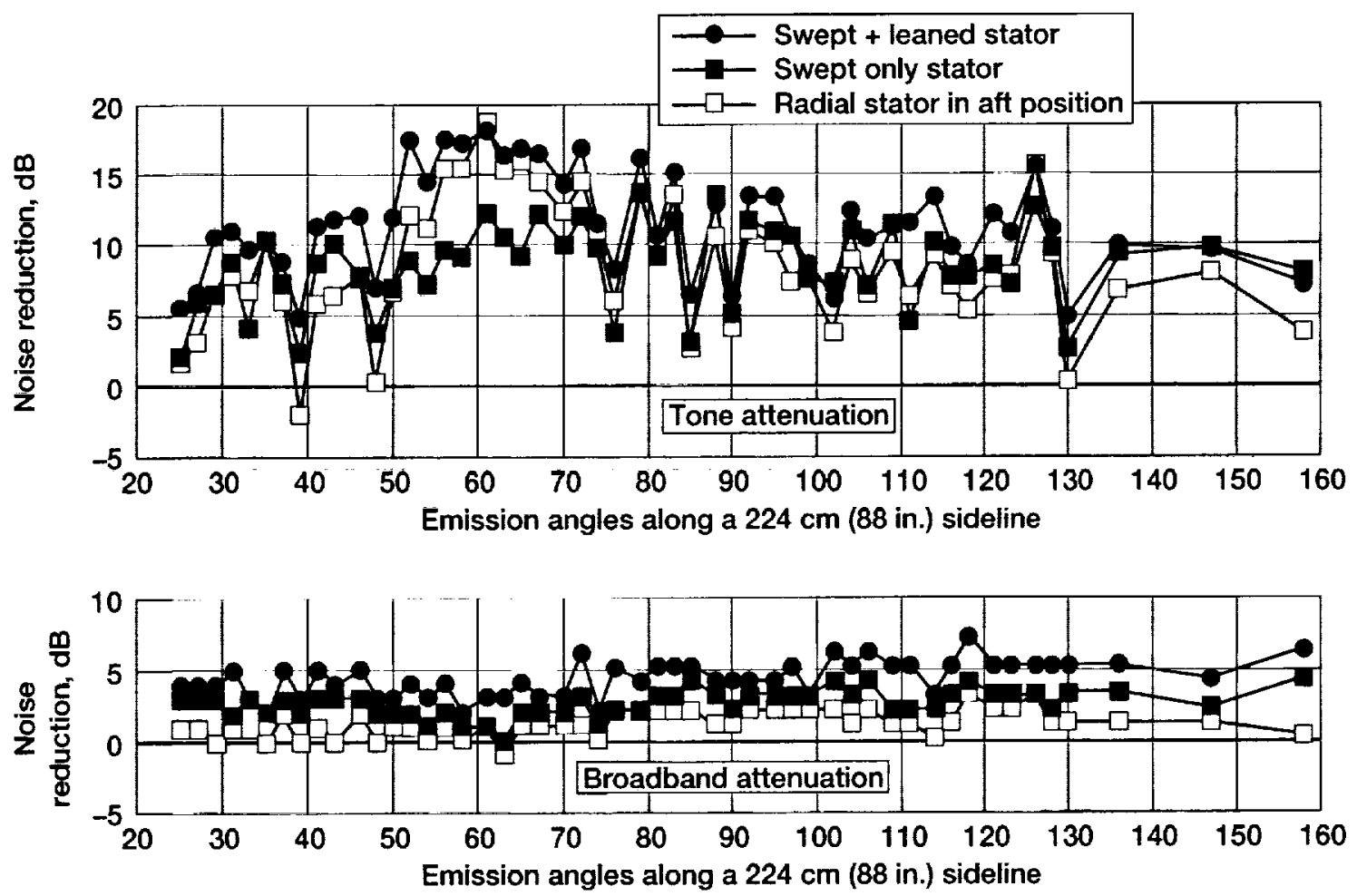

Figure 19.-Sideline constant bandwidth $(59 \mathrm{~Hz})$ directivities showing noise reduction relative to baseline configuration with the radial stator in the forward (upstream) position (50 percent fan design speed, SPL at 3BPF).

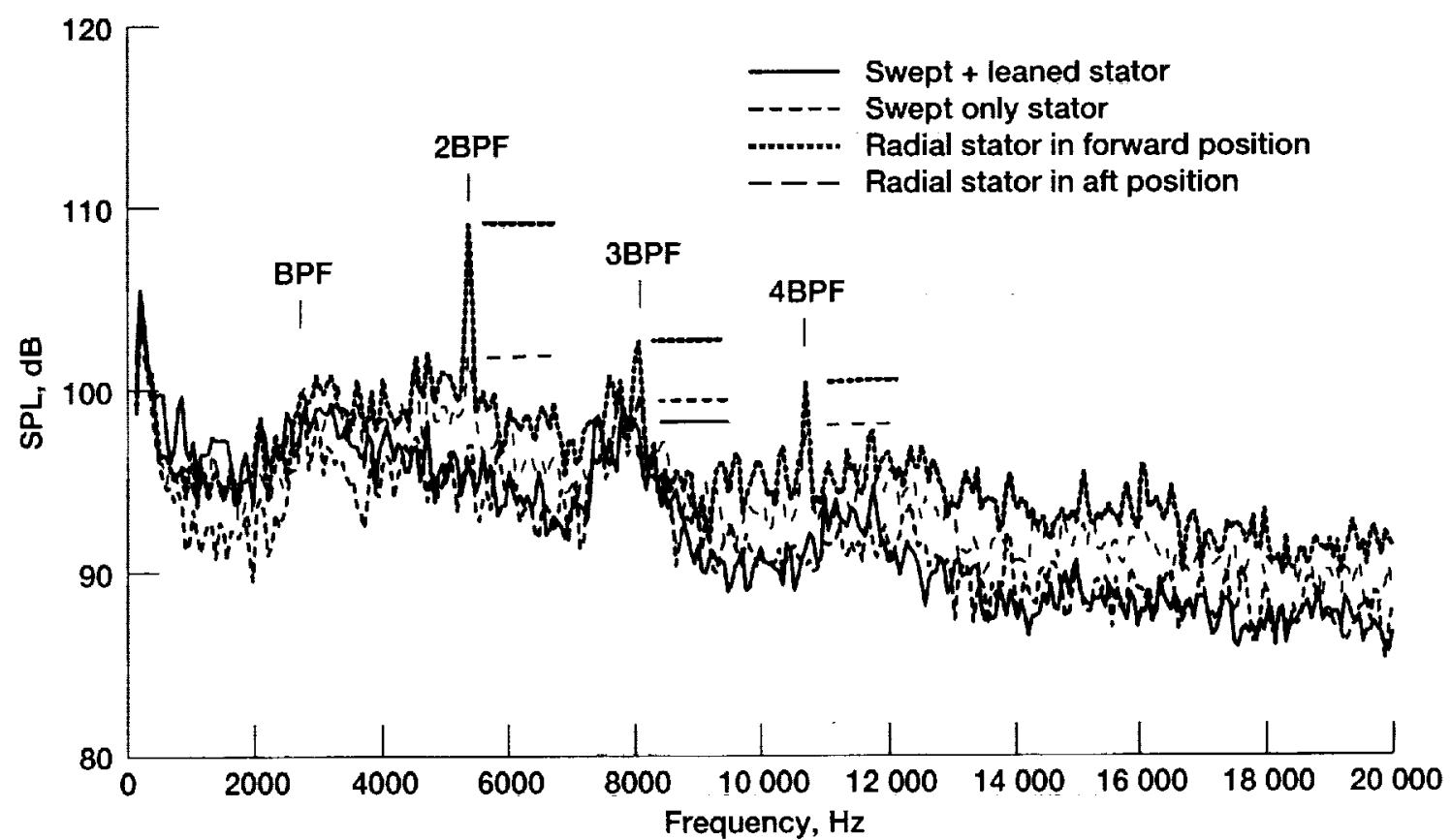

Figure 20.-Constant bandwidth $(59 \mathrm{~Hz})$ spectra on a $224 \mathrm{~cm}\left(88 \mathrm{in}\right.$.) sideline at $126^{\circ}$ from inlet axis. Fan is operating at 84 percent design speed. 

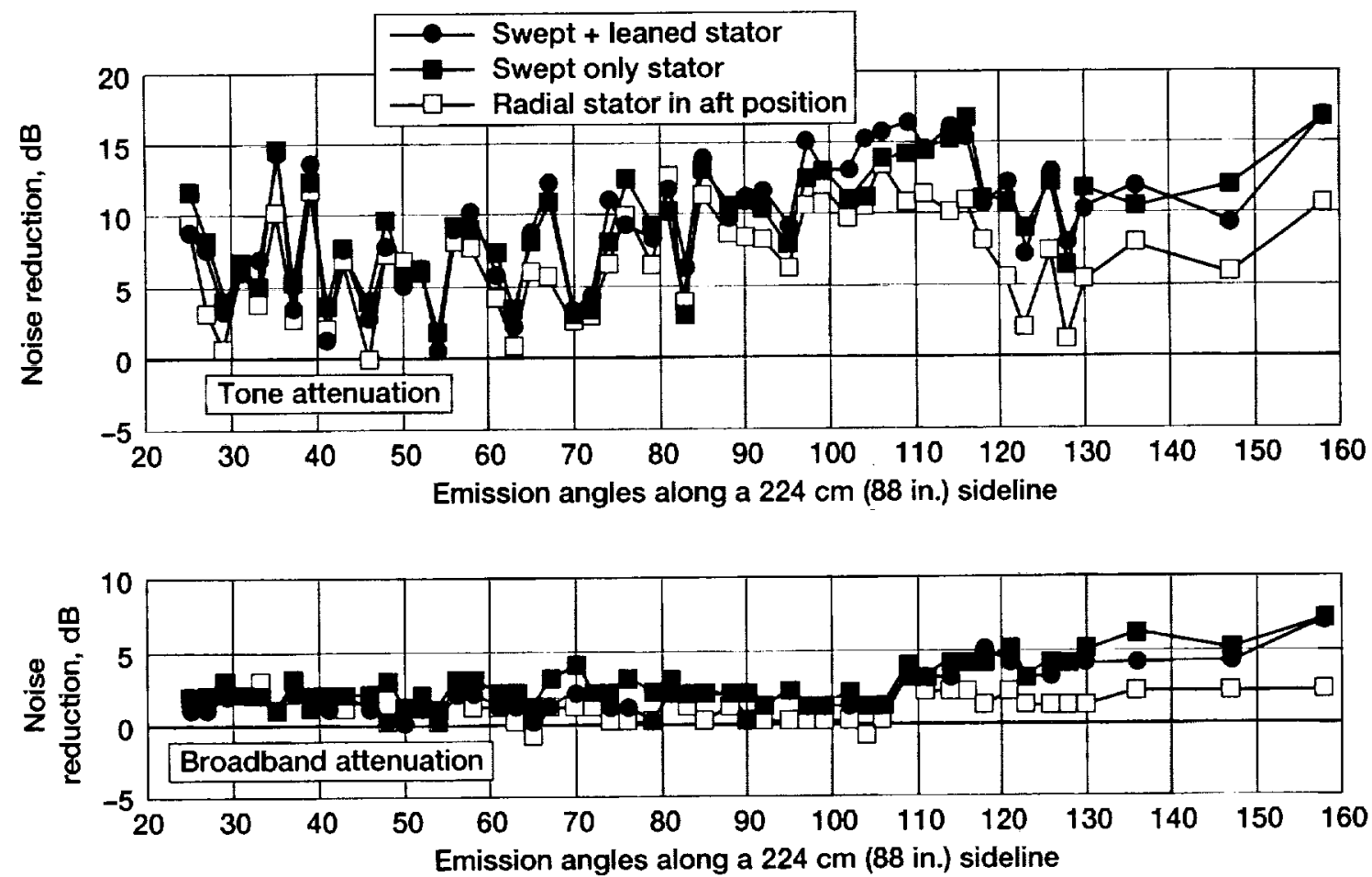

Figure 21.-Sideline constant bandwidth $(59 \mathrm{~Hz})$ directivities showing noise reduction relative to baseline configuration with the radial stator in the forward (upstream) position (84 percent fan design speed, SPL at 2BPF.
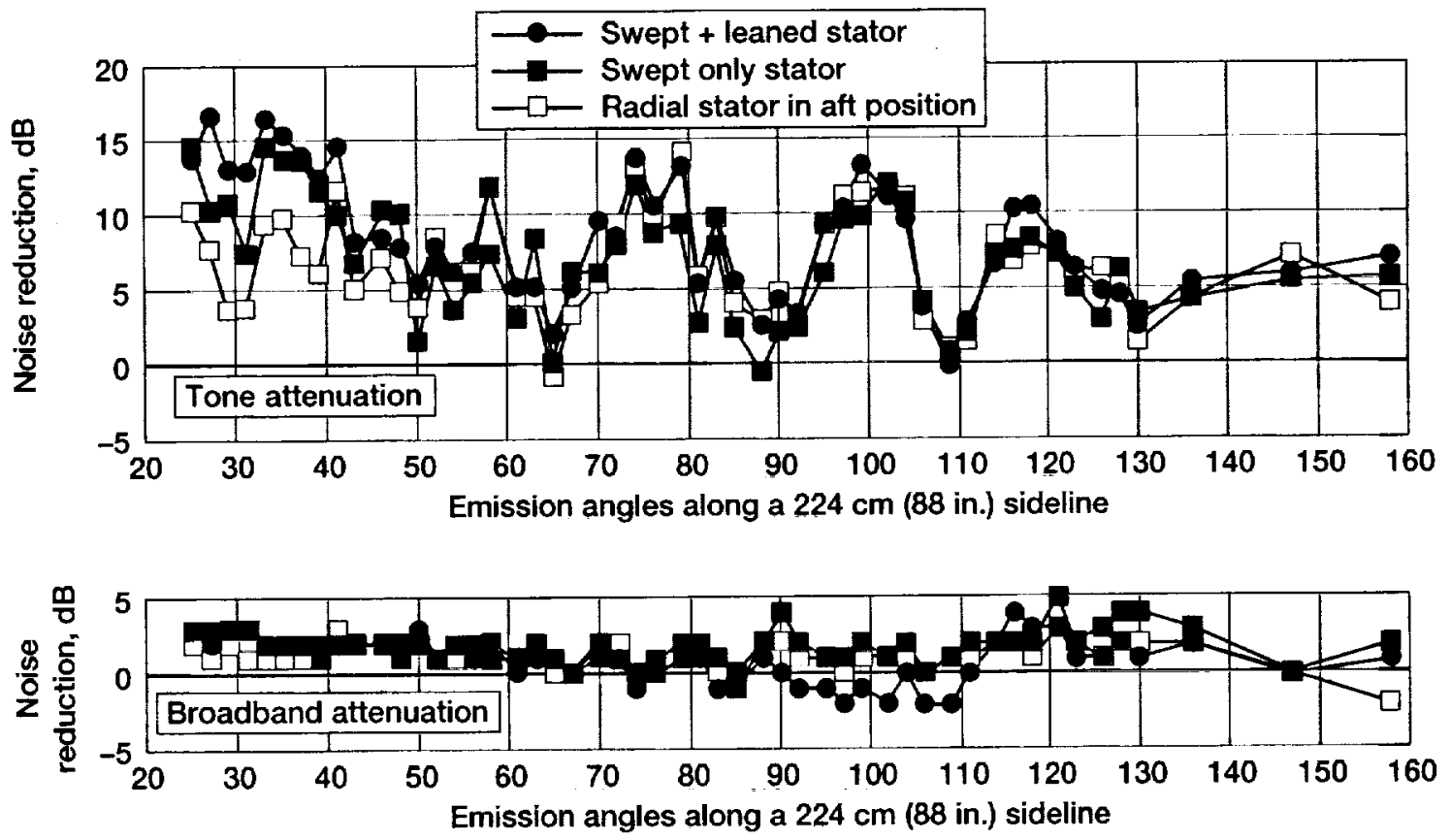

Figure 22. - Sideline constant bandwidth $(59 \mathrm{~Hz})$ directivities showing noise reduction relative to baseline configuration with the radial stator in the forward (upstream) position (84 percent fan design speed, SPL at 3BPF). 


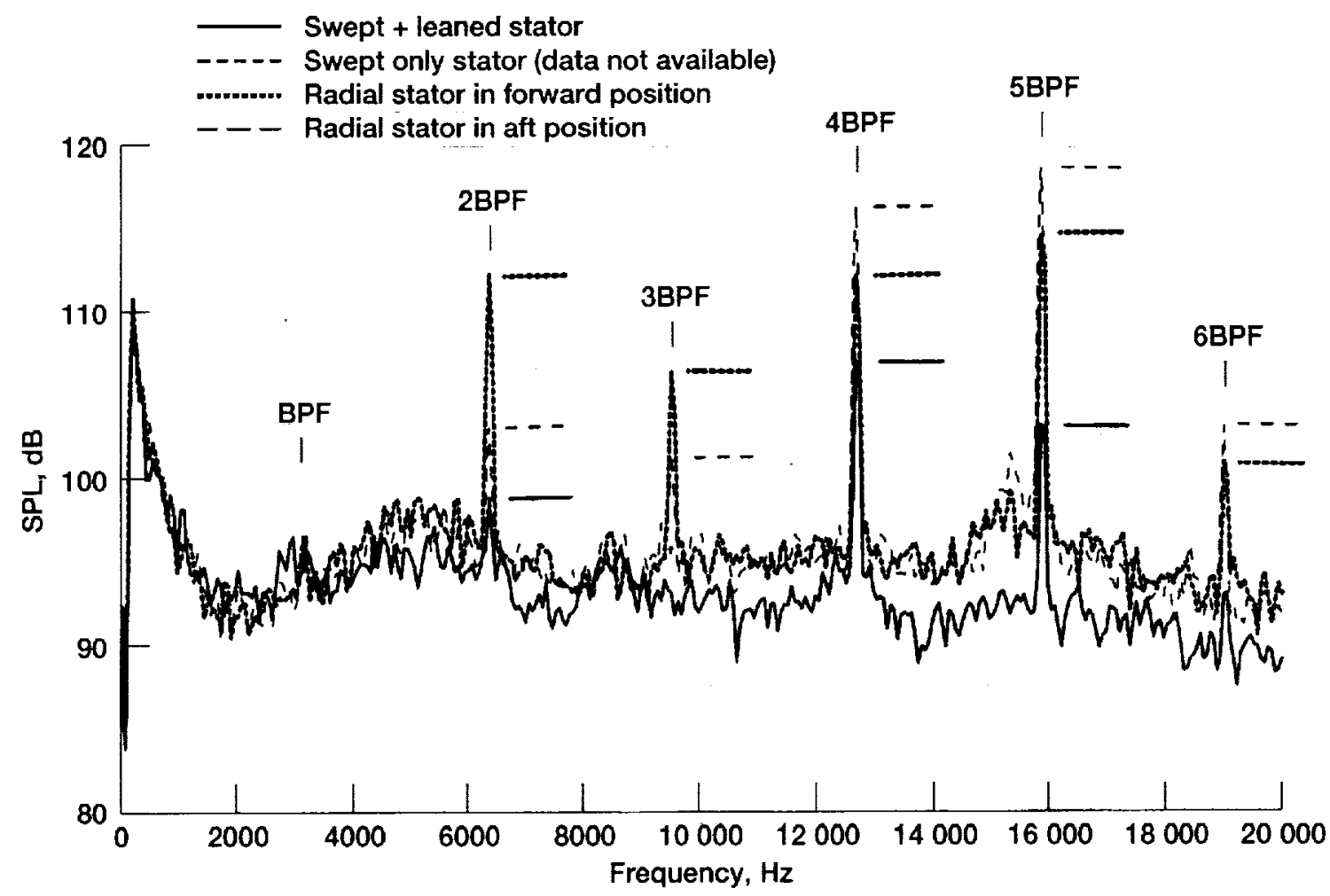

Figure 23.-Constant bandwidth $(59 \mathrm{~Hz})$ spectra on a $224 \mathrm{~cm}\left(88 \mathrm{in}\right.$.) sideline at $126^{\circ}$ from inlet axis. Fan is operating at 100 percent design speed.
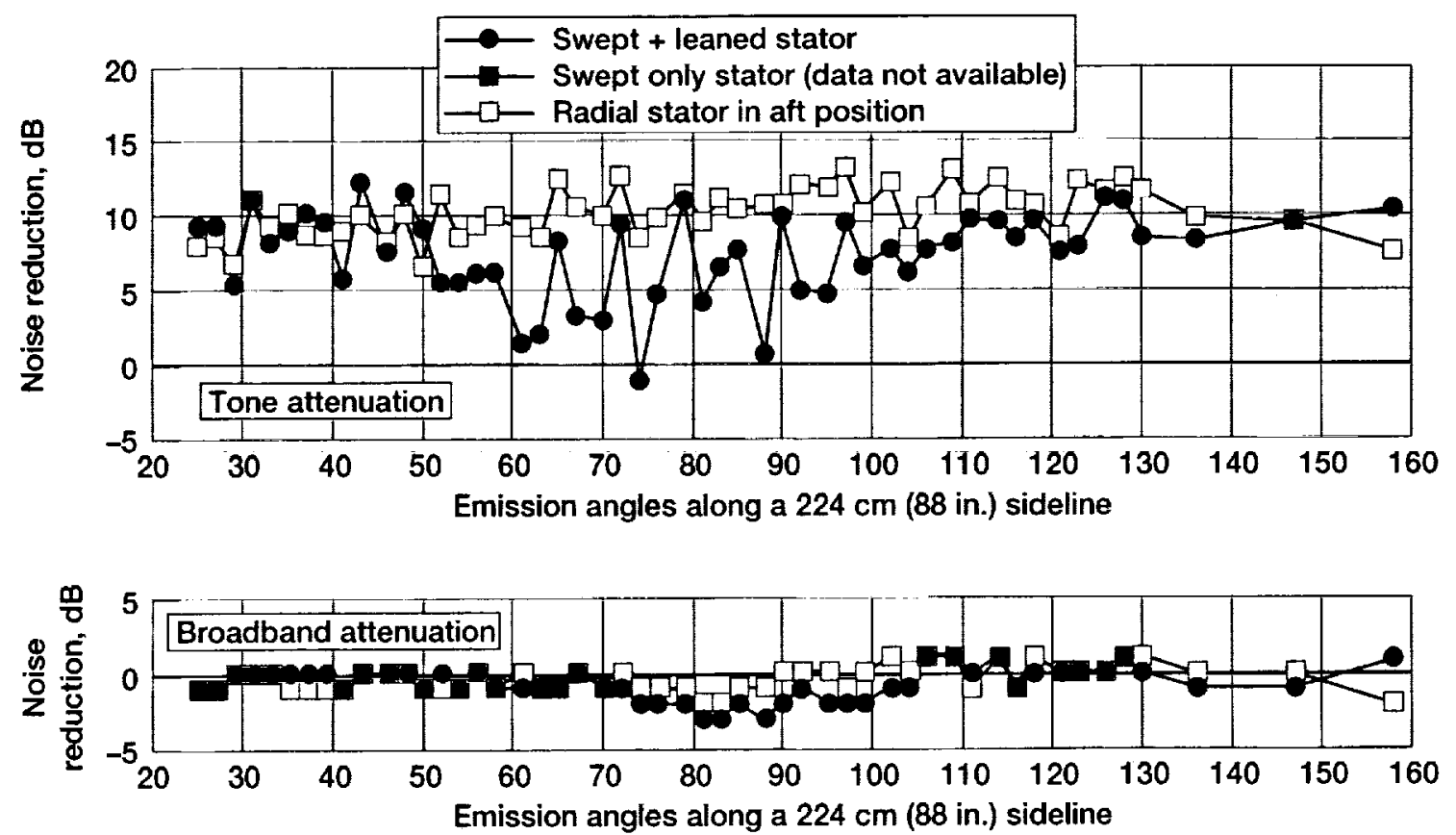

Figure 24.-Sideline constant bandwidth $(59 \mathrm{~Hz})$ directivities showing noise reduction relative to baseline configuration with the radial stator in the forward (upstream) position (100 percent fan design speed, SPL at 1BPF). 

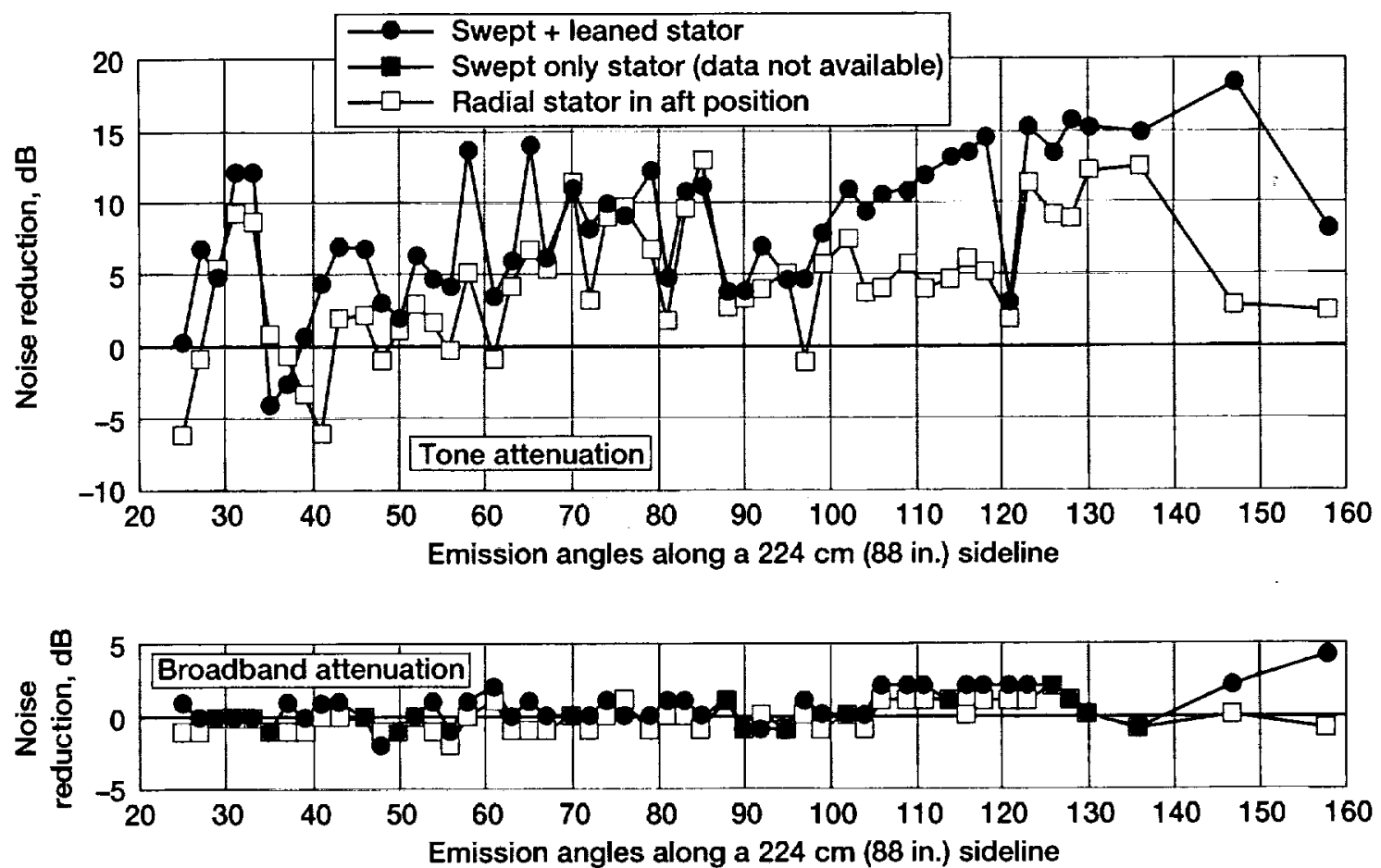

Figure 25.-Sideline constant bandwidth $(59 \mathrm{~Hz})$ directivities showing noise reduction relative to baseline configuration with the radial stator in the forward (upstream) position (100 percent fan design speed, SPL at 2BPF).
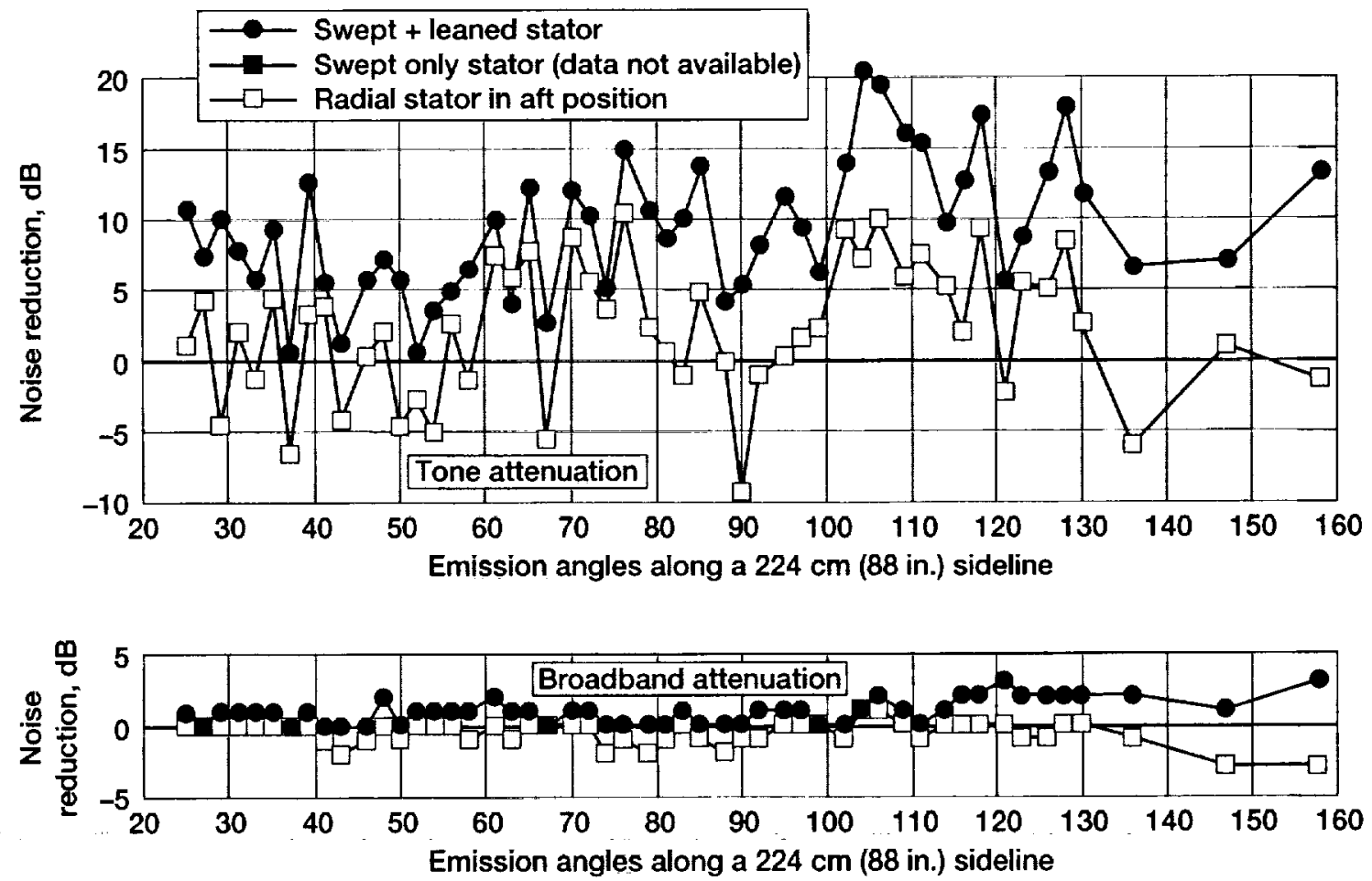

Figure 26.-Sideline constant bandwidth $(59 \mathrm{~Hz})$ directivities showing noise reduction relative to baseline configuration with the radial stator in the forward (upstream) position (100 percent fan design speed, SPL at 3BPF). 


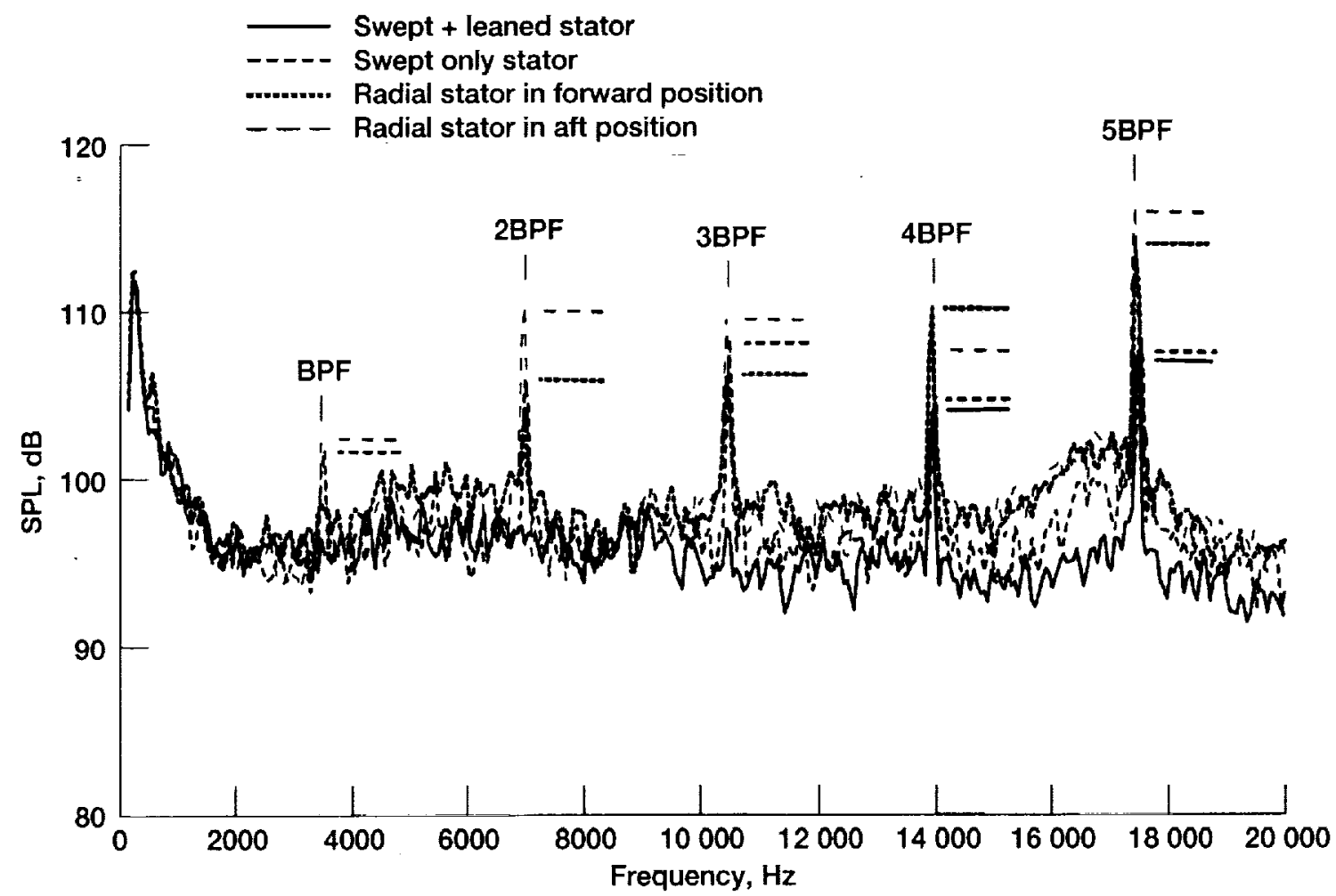

Figure 27.-Constant bandwidth $(59 \mathrm{~Hz})$ spectra on a $224 \mathrm{~cm}\left(88 \mathrm{in}\right.$.) sideline at $126^{\circ}$ from inlet axis. Fan is operating at 110 percent design speed.
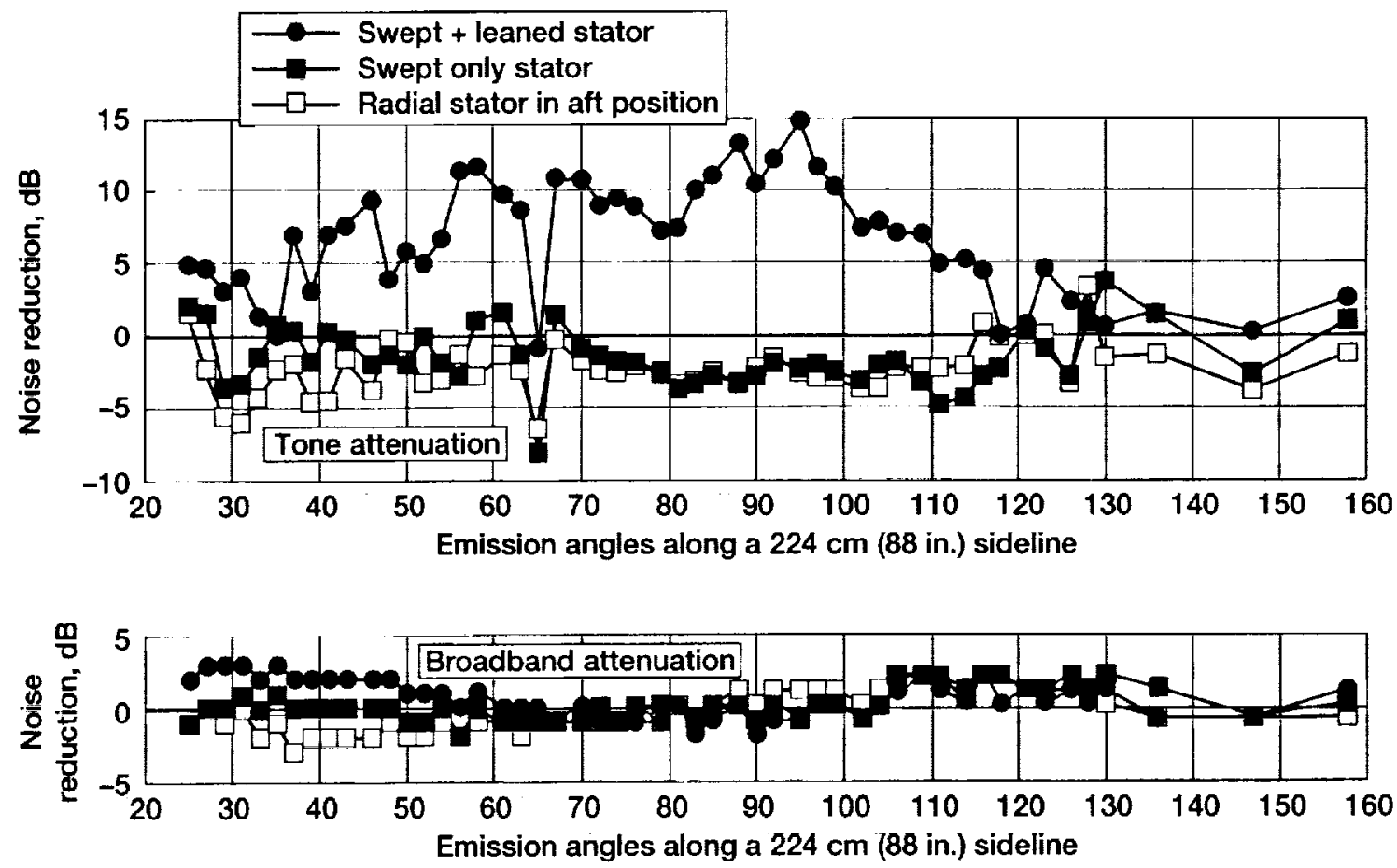

Figure 28.-Sideline constant bandwidth $(59 \mathrm{~Hz})$ directivities showing noise reduction relative to baseline configuration with the radial stator in the forward (upstream) position (110 percent fan design speed, SPL at 1BPF). 

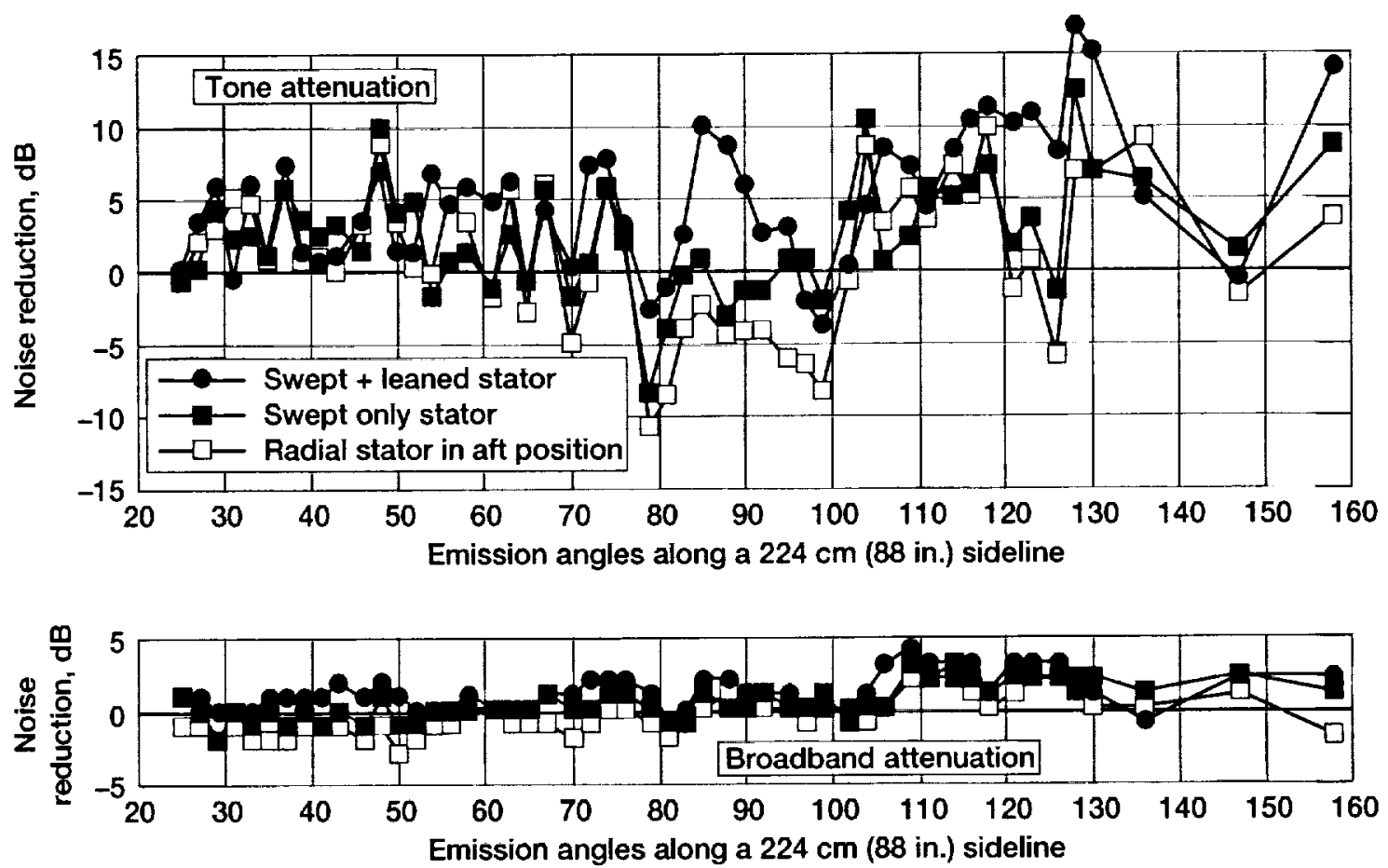

Figure 29.-Sideline constant bandwidth $(59 \mathrm{~Hz})$ directivities showing noise reduction relative to baseline configuration with the radial stator in the forward (upstream) position (110 percent fan design speed, SPL at 2BPF).
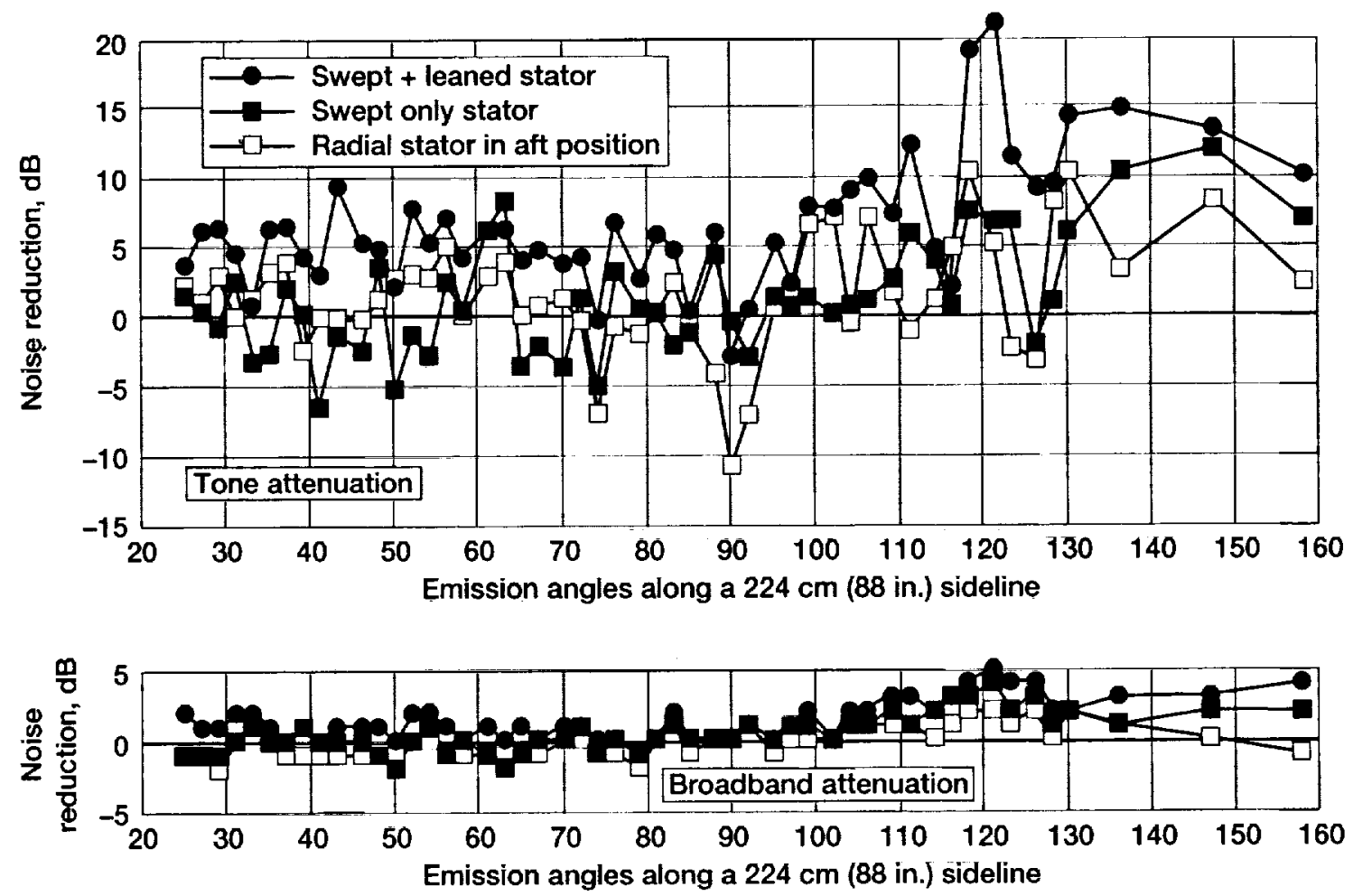

Figure 30.-Sideline constant bandwidth $(59 \mathrm{~Hz})$ directivities showing noise reduction relative to baseline configuration with the radial stator in the forward (upstream) position (110 percent fan design speed, SPL at 3BPF). 

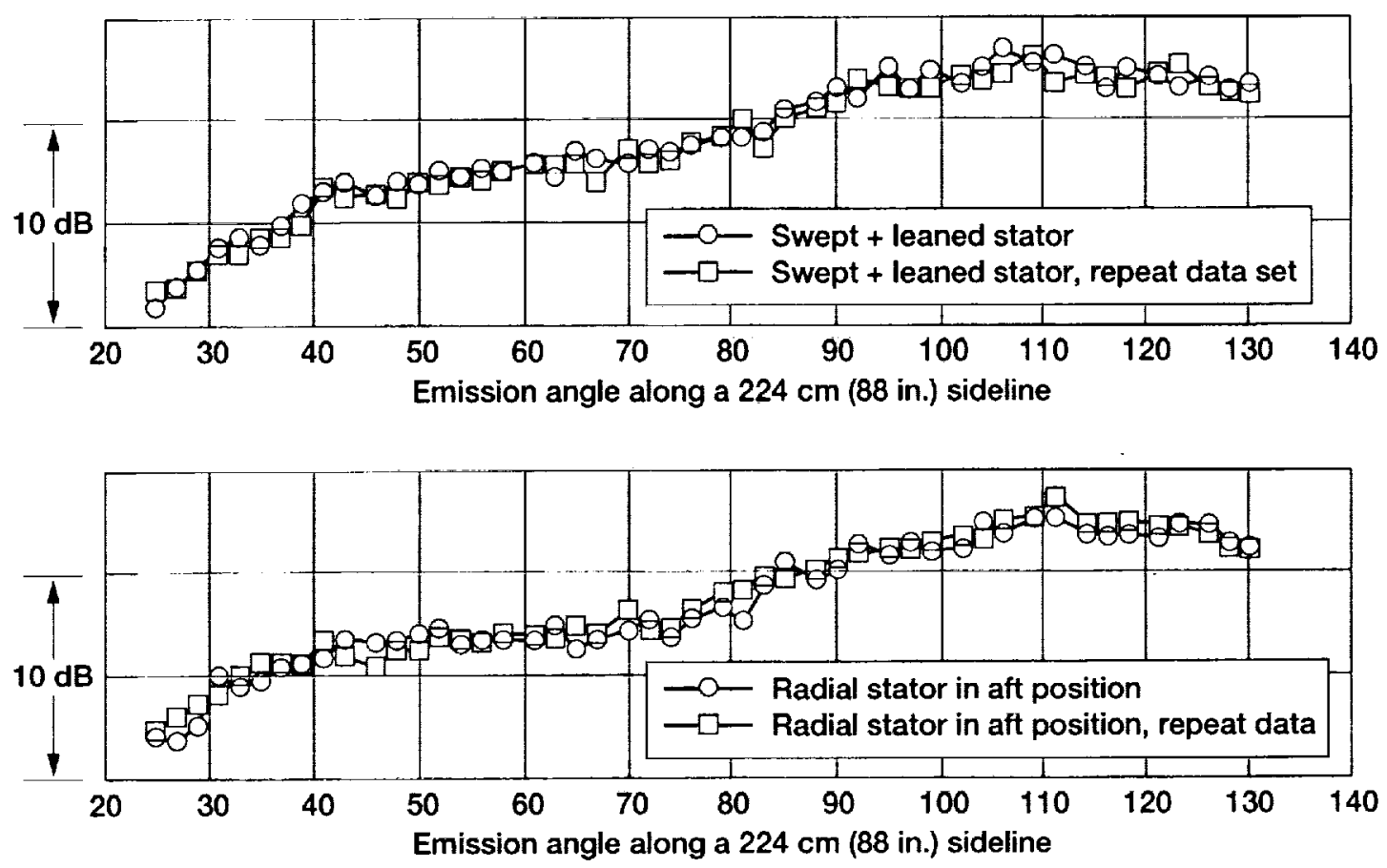

Figure 31.-Data comparison for two builds of the same stator configuration showing data repeatability. (1/3rd octave directivities at $2500 \mathrm{~Hz}, 84$ percent design speed.)
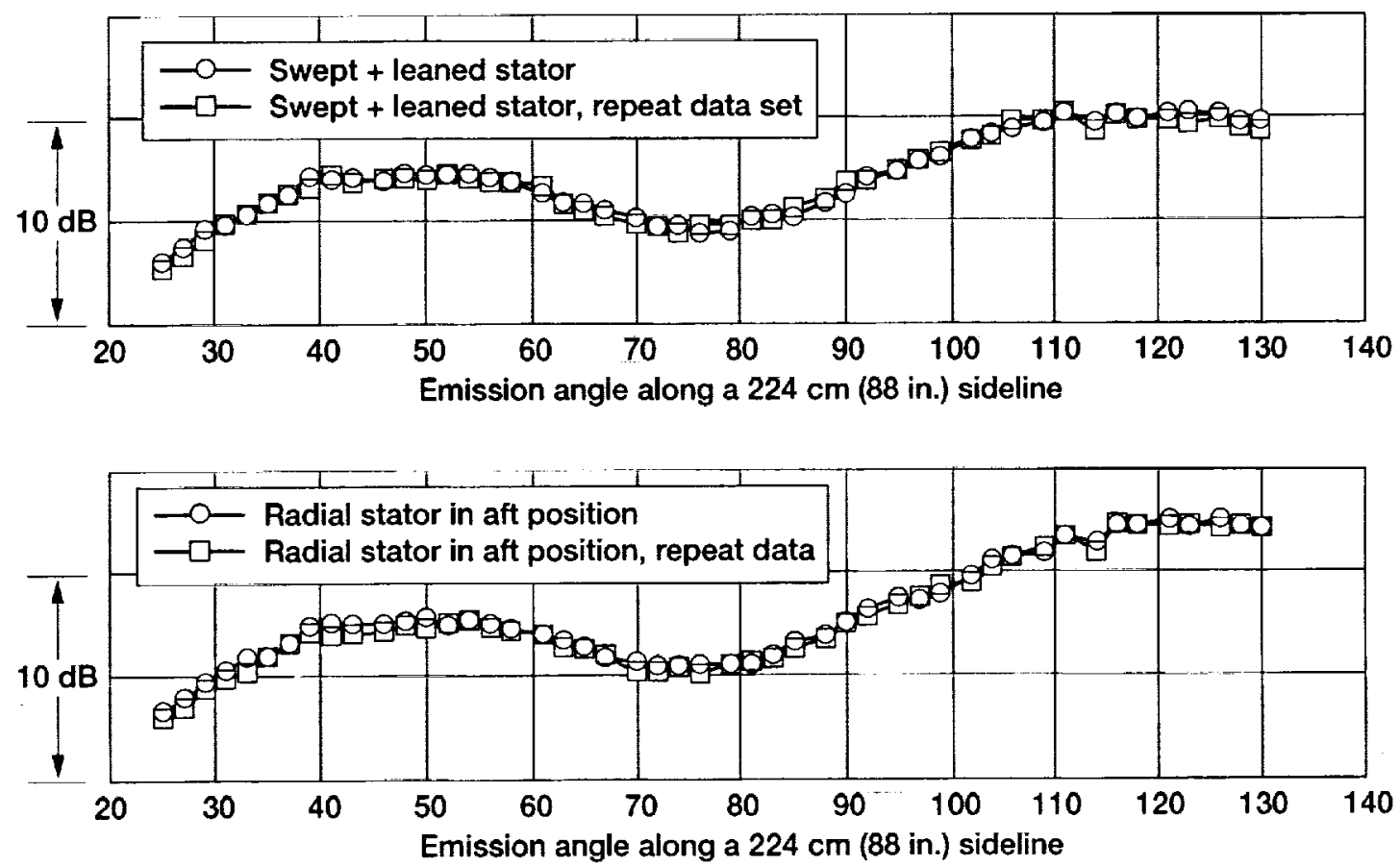

Figure 32.-Data comparison for two builds of the same stator configuration showing data repeatability. (1/3rd octave directivities at $20000 \mathrm{~Hz}, 84$ percent design speed.) 

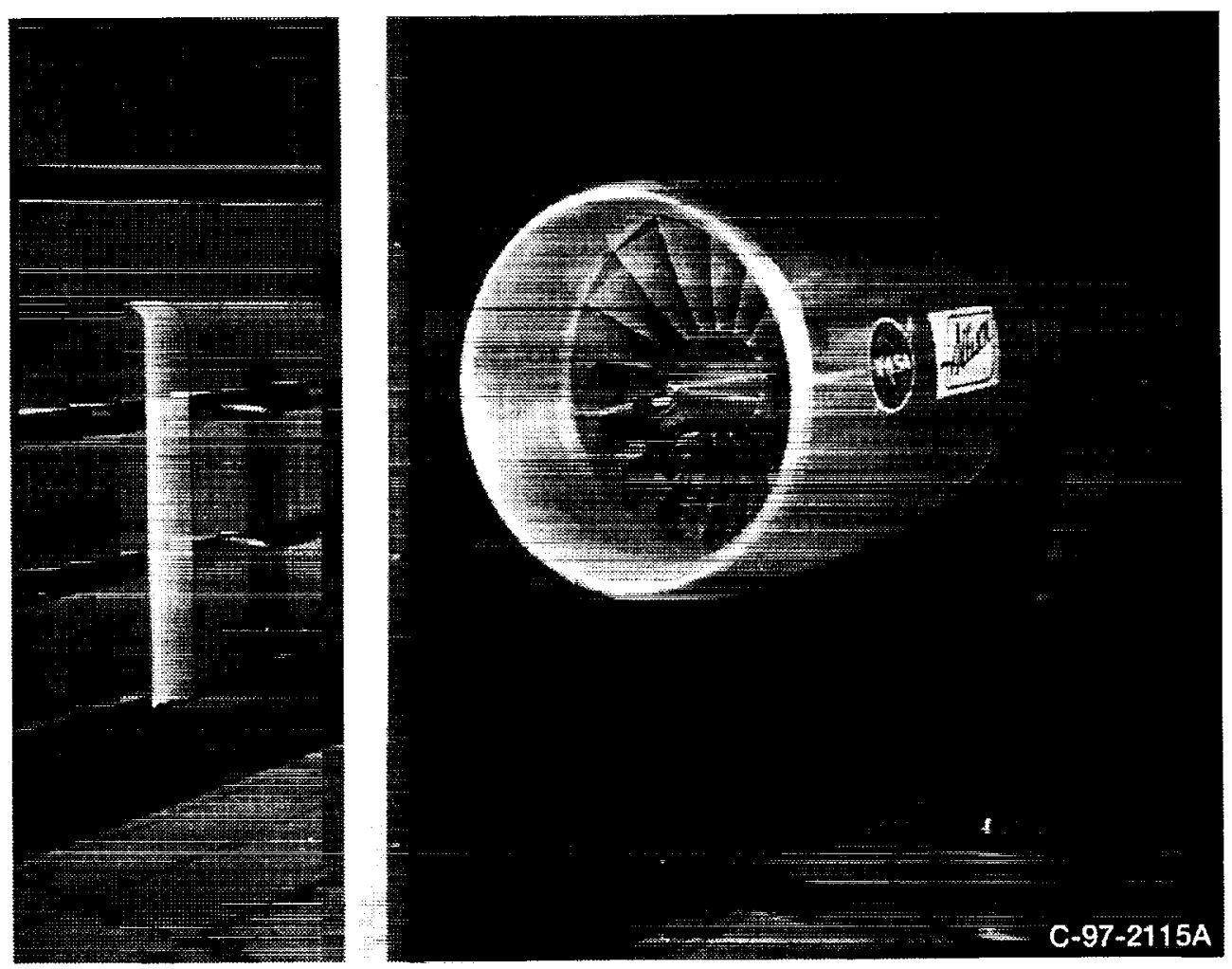

Figure 33.-Photograph of the Allison fan installed in the 9x15 LSWT with the acoustic barrier wall in place. The wall is shown in its upstream position with the wall leading edge at the fan inlet highlight.
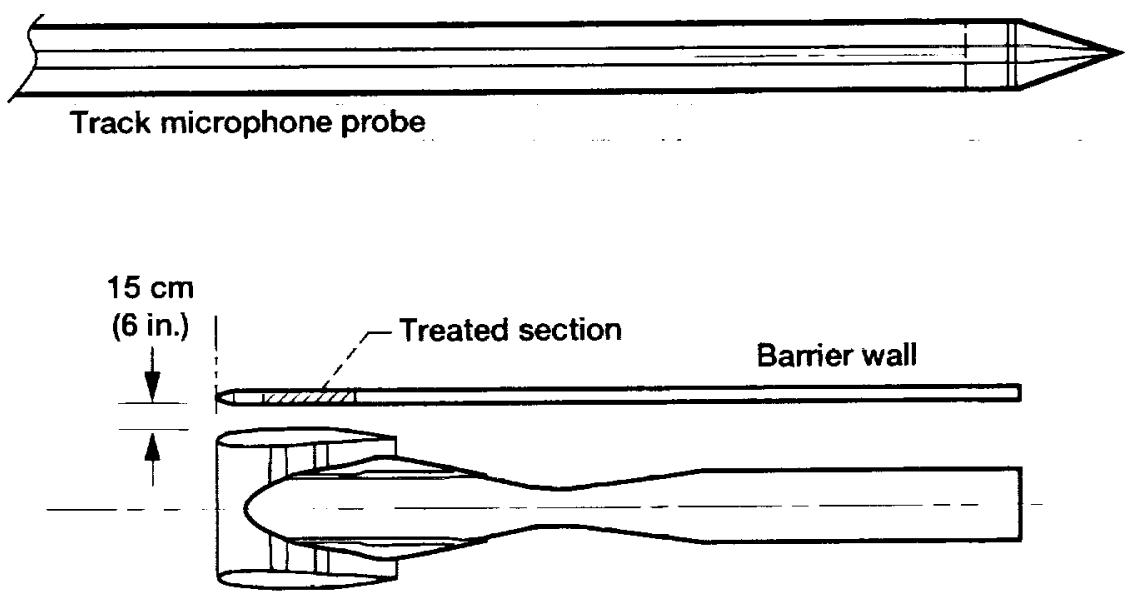

Figure 34.-Sketch of the acoustic barrier wall installed in the 9x15 LSWT. 


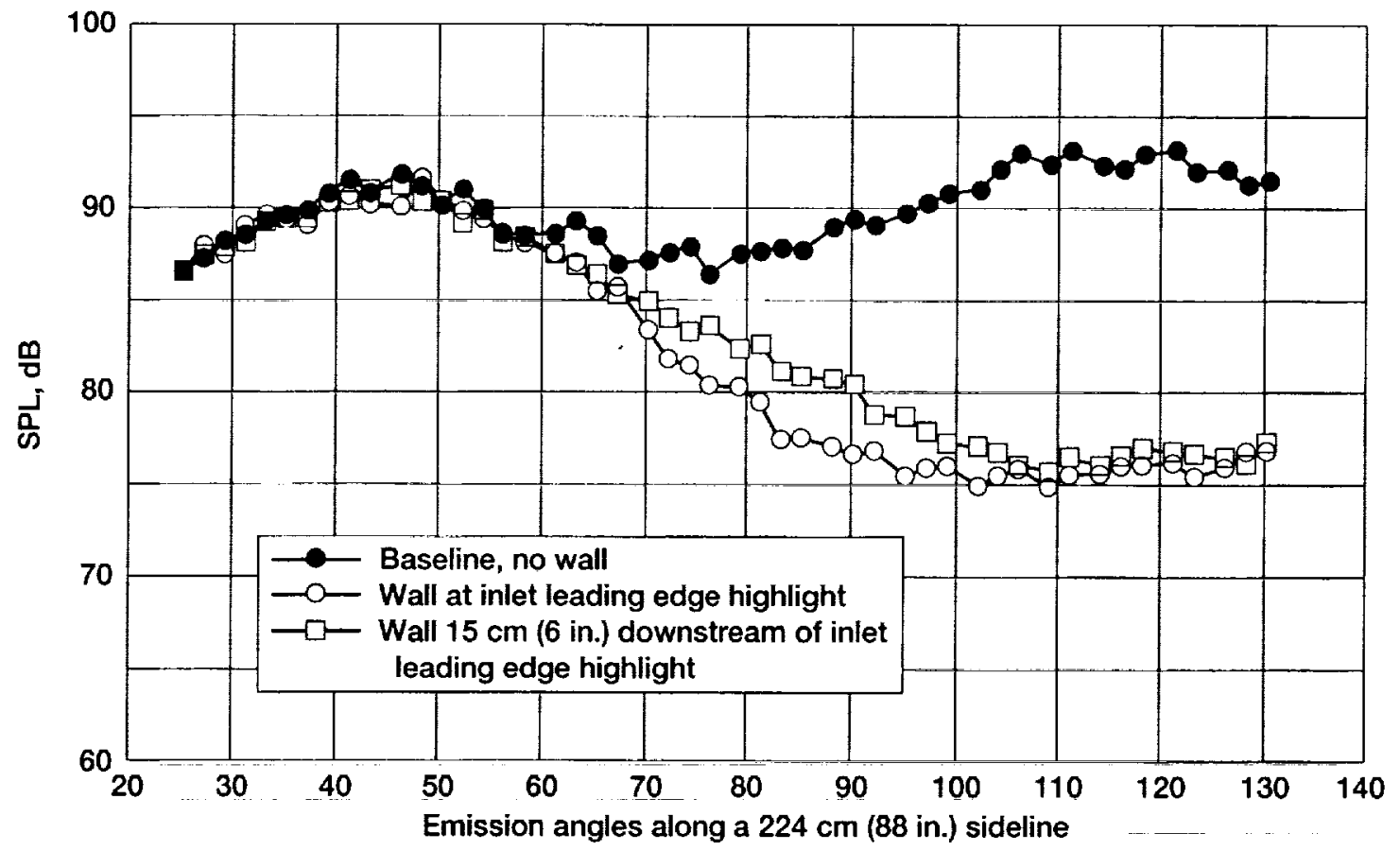

Figure 35.-Effect of acoustic barrier wall (50 percent design speed, broadband at $2500 \mathrm{~Hz}$ ).

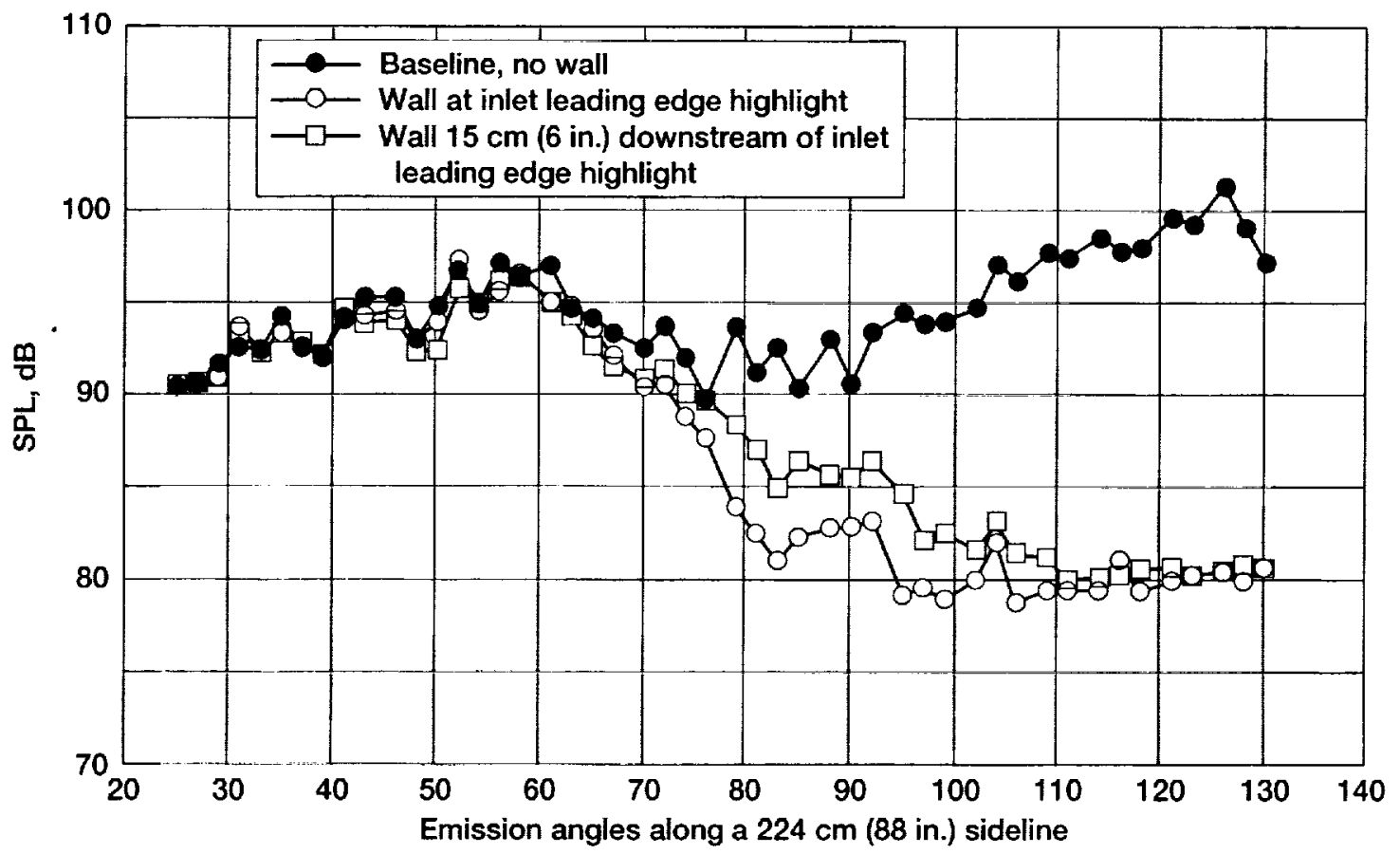

Figure 36.-Effect of acoustic barrier wall (50 percent design speed, 3BPF at $5000 \mathrm{~Hz}$ ). 


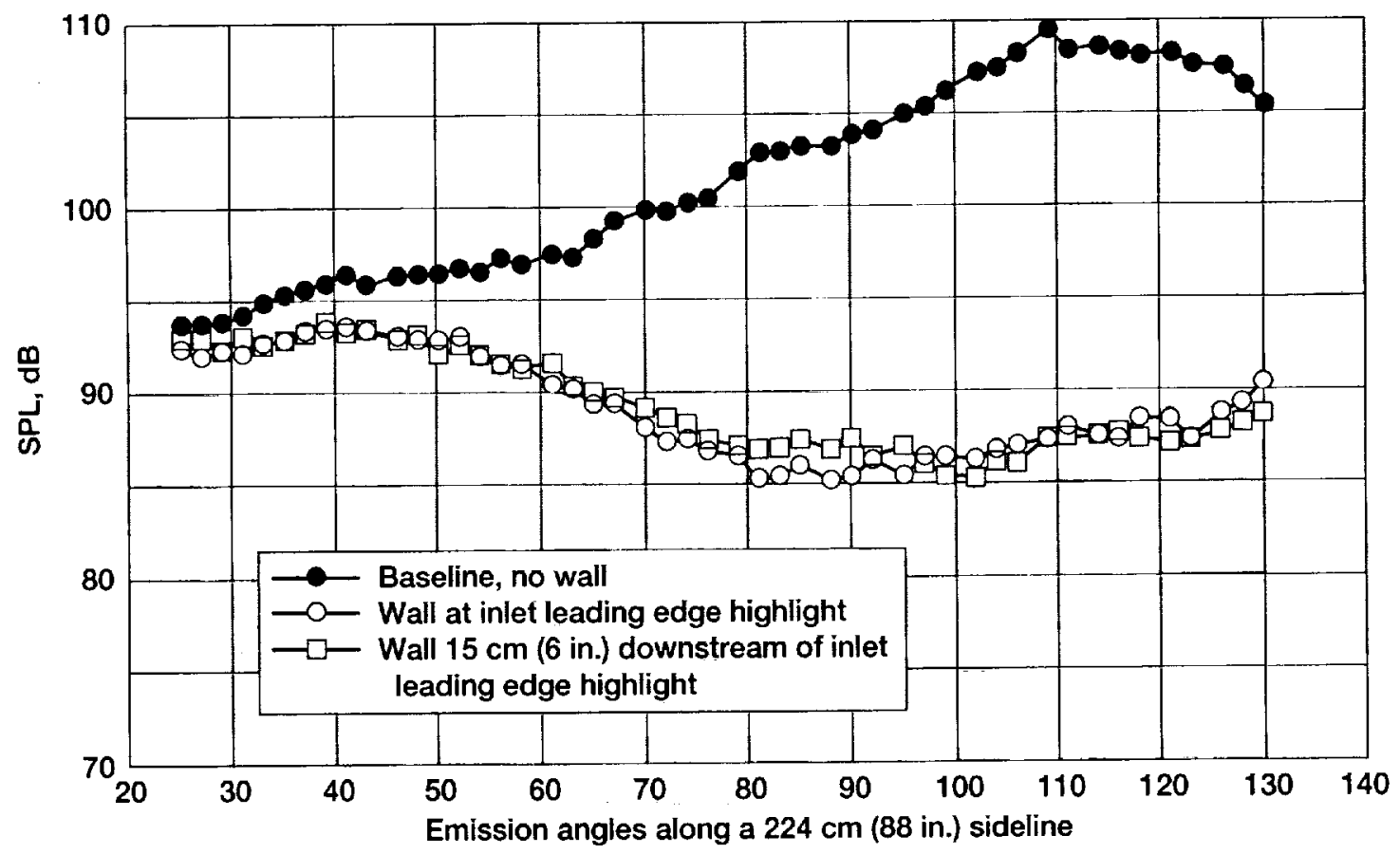

Figure 37.-Effect of acoustic barrier wall (100 percent design speed, broadband at $4000 \mathrm{~Hz}$ ).

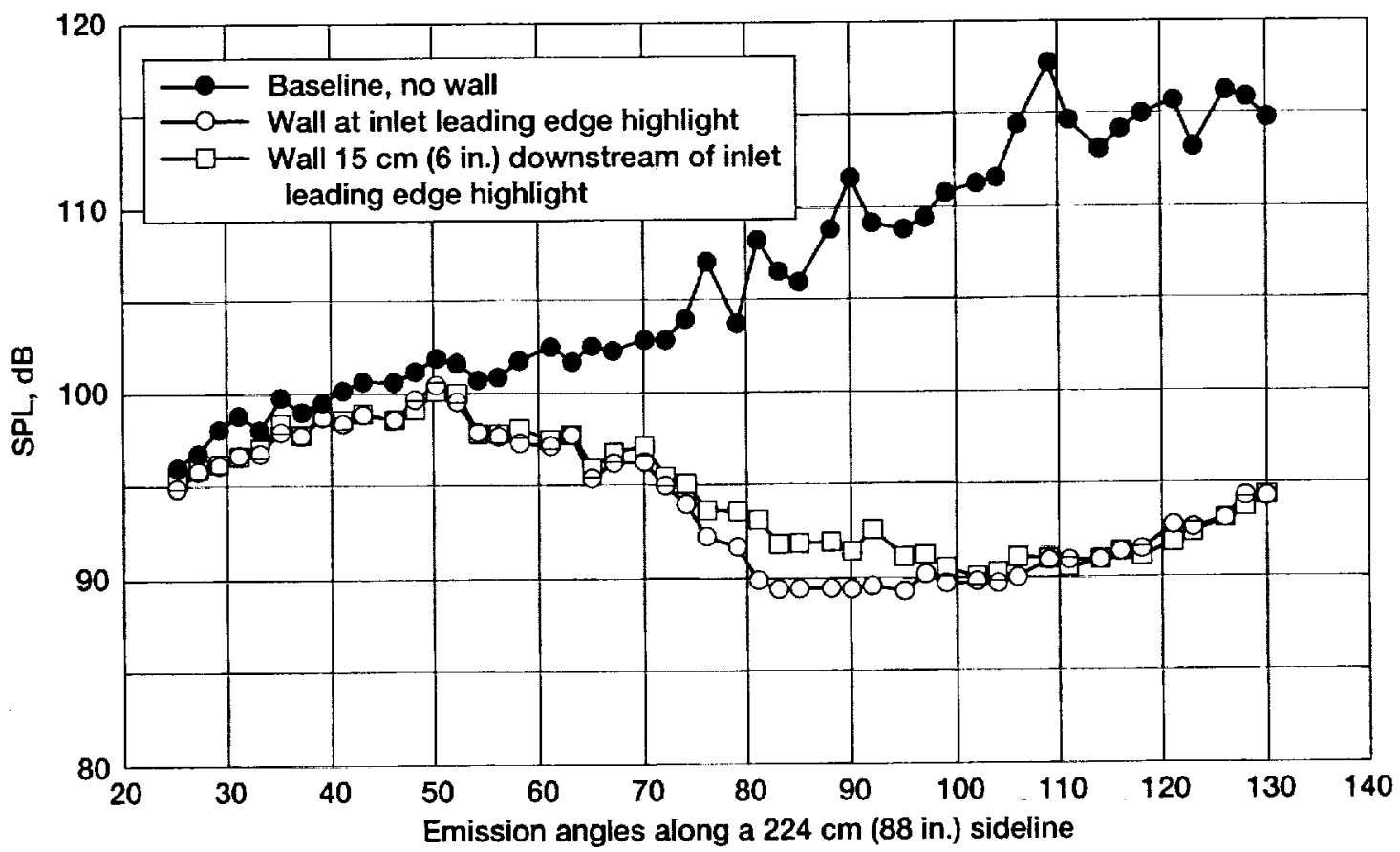

Figure 38.-Effect of acoustic barrier wall (100 percent design speed, 4BPF at $12500 \mathrm{~Hz}$ ). 


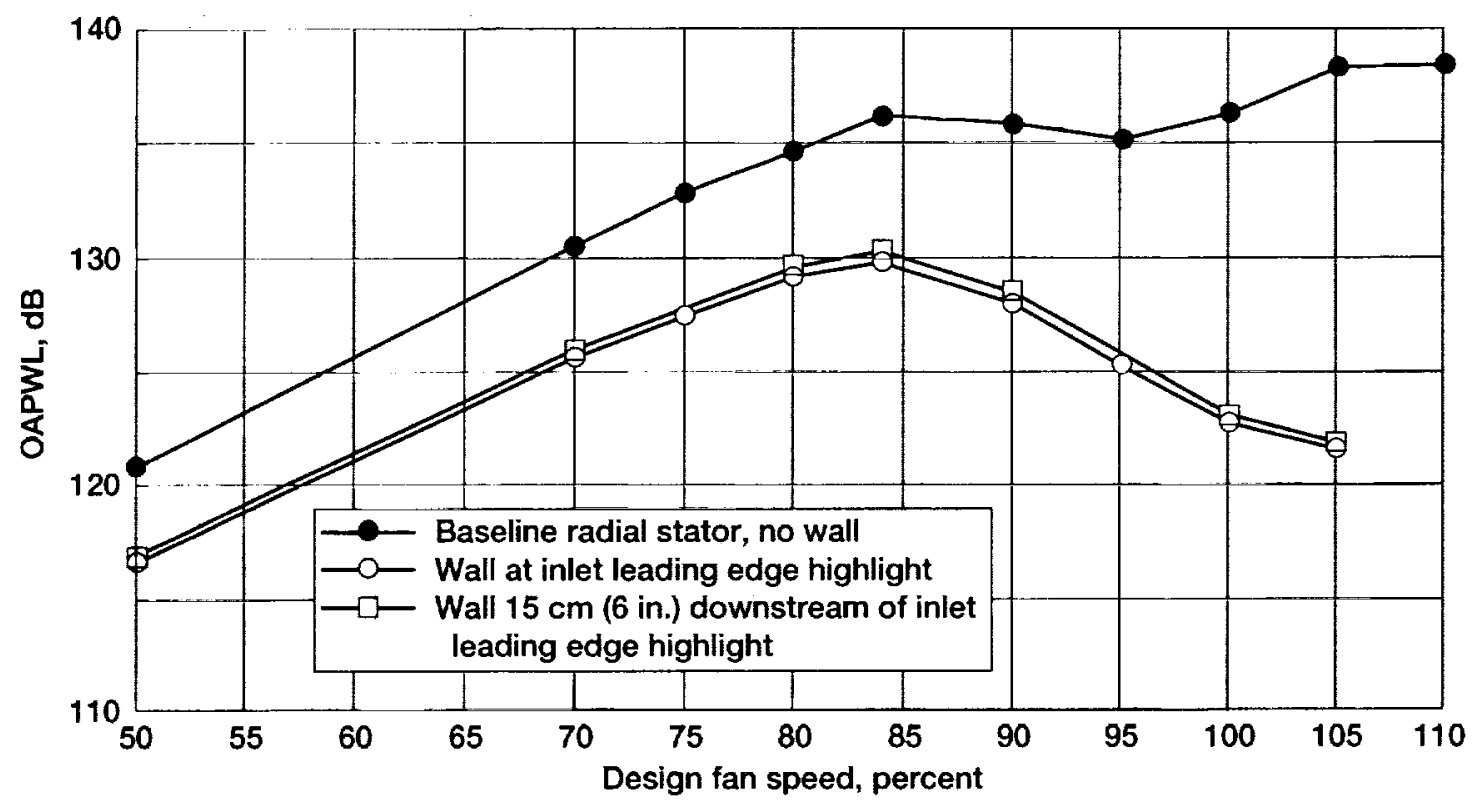

Figure 39.-Effect of barrier wall on 1/3rd octave overall sound power level measured form 2000 to $20000 \mathrm{~Hz}$. (Data from translating microphone probe.)

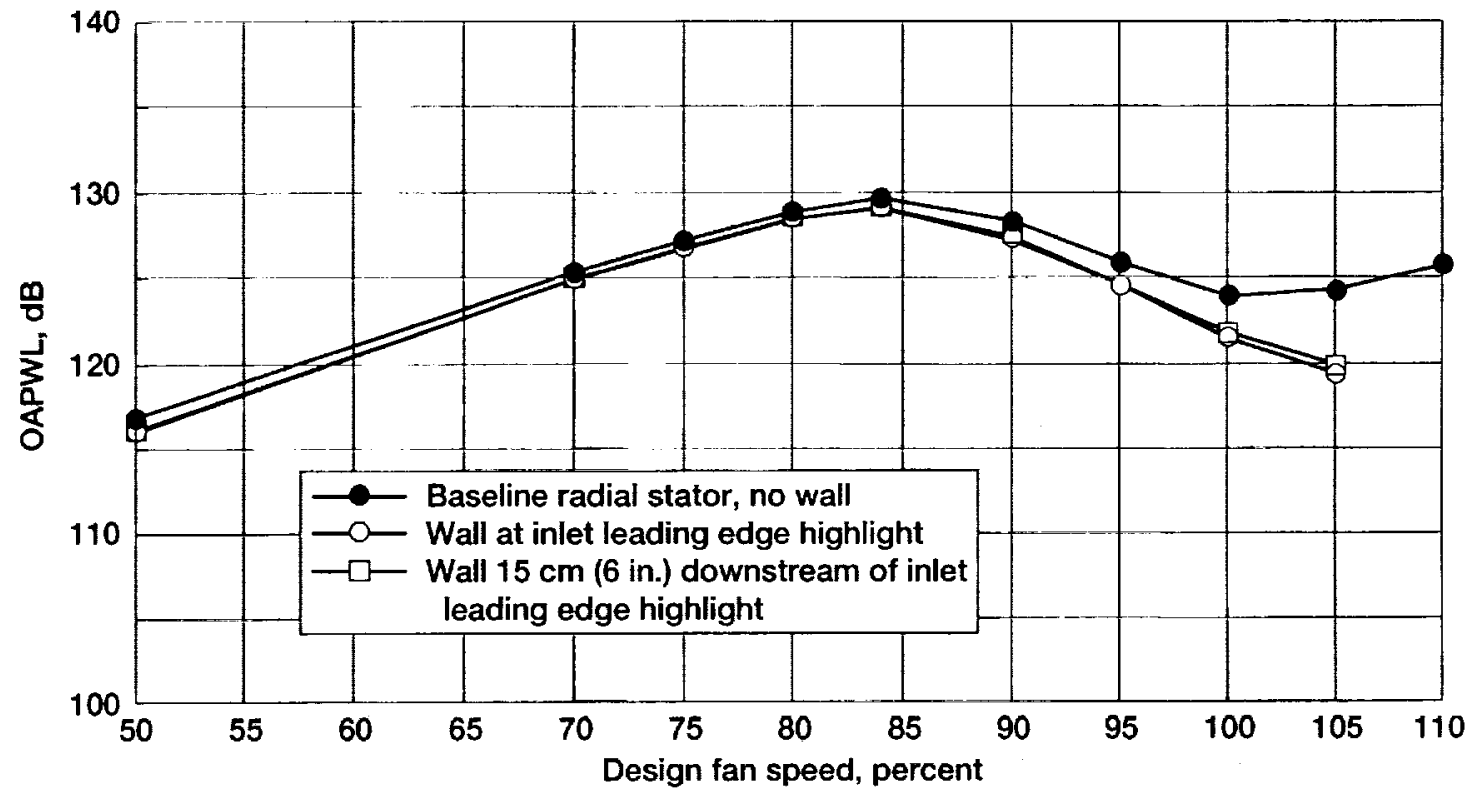

Figure 40.-Effect of barrier wall on 1/3rd octave overall sound power level measured form 2000 to $20000 \mathrm{~Hz}$ for emission angles from 25 to $61^{\circ}$. (Data from translating microphone probe.) 


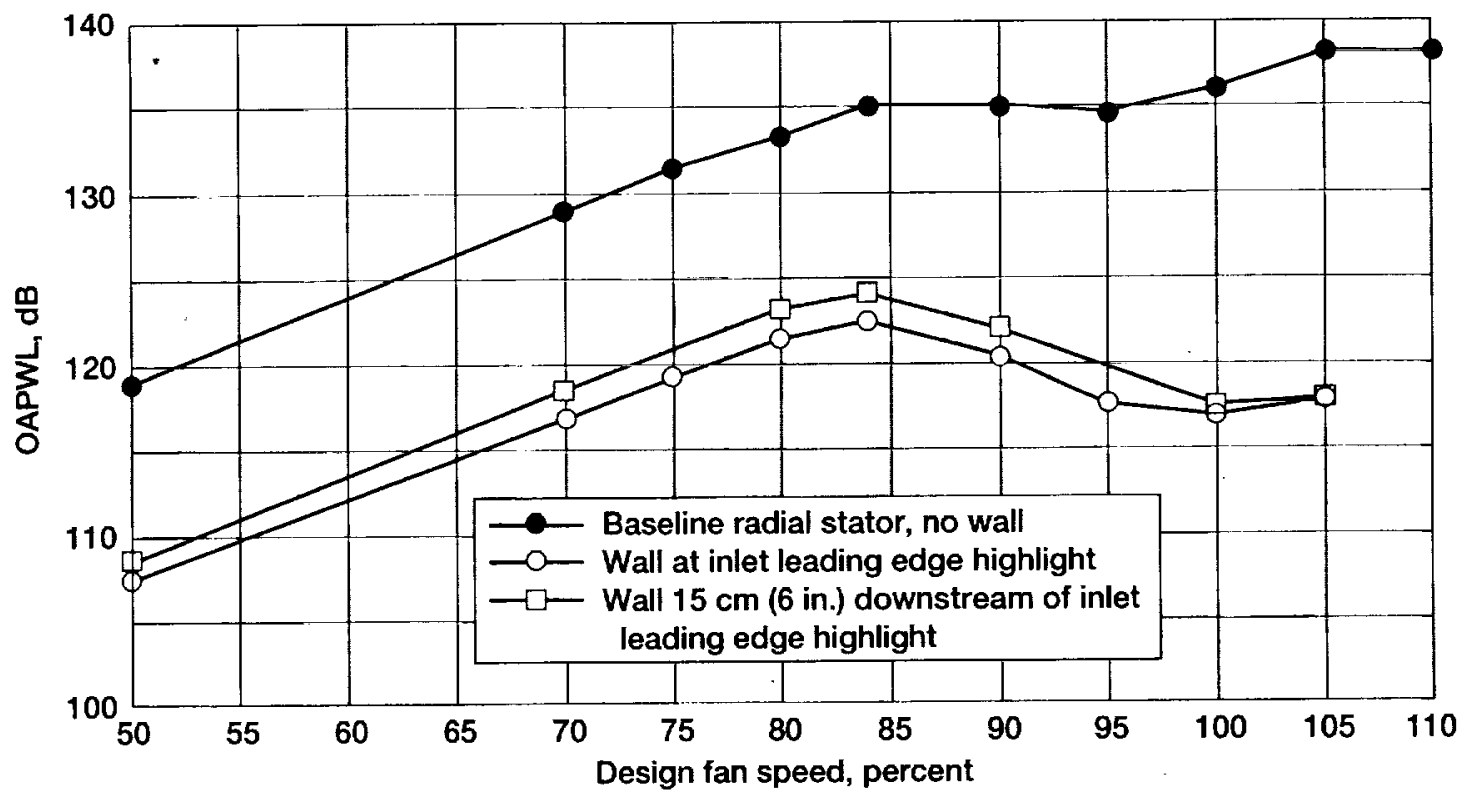

Figure 41.-Effect of barrier wall on 1/3rd octave overall sound power level measured form 2000 to $20000 \mathrm{~Hz}$ for emission angles from 61 to $130^{\circ}$. (Data from translating microphone probe.)

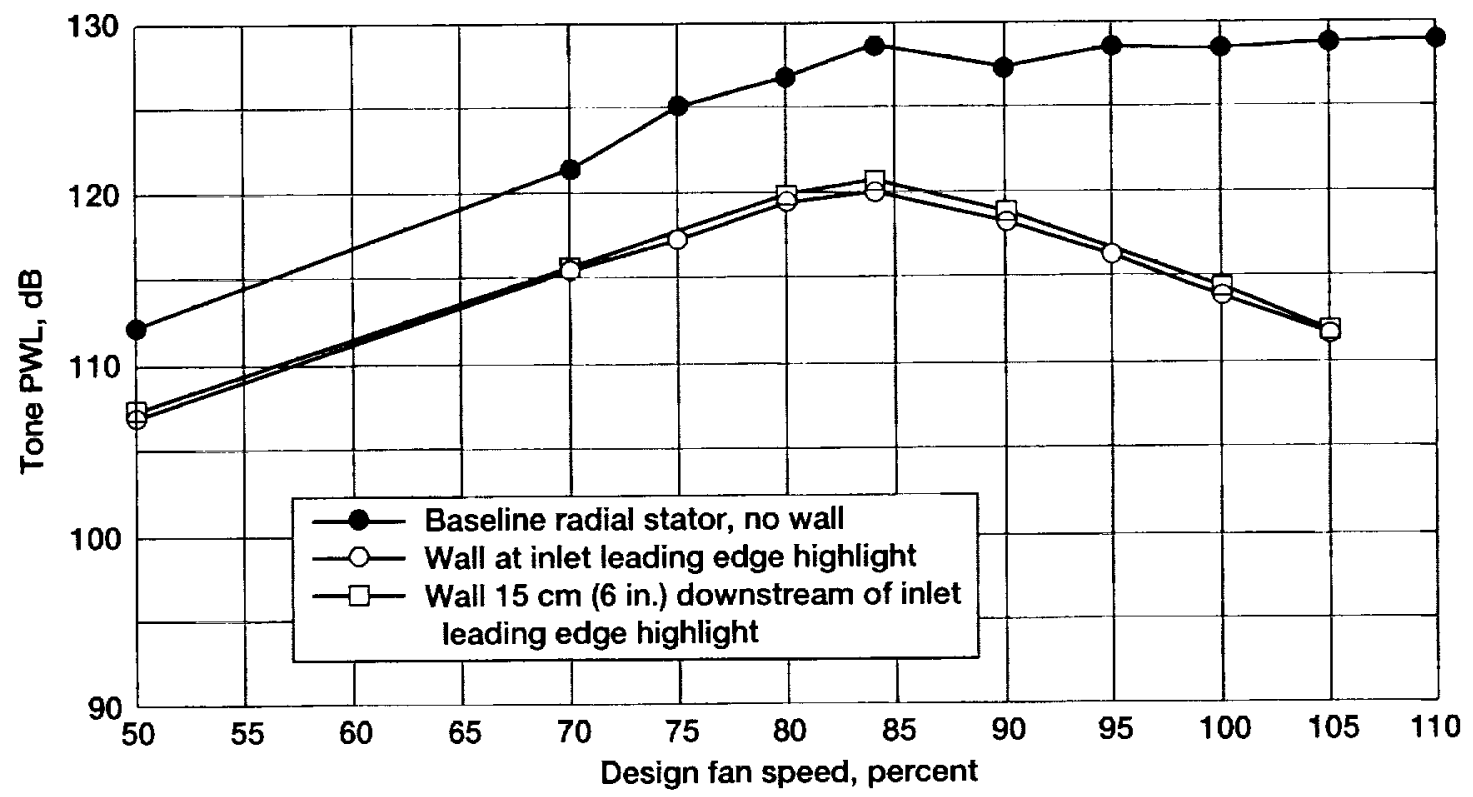

Figure 42.-Effect of barrier wall on 1/3rd octave 2BPF tone sound power level. (Data from translating microphone probe.) 


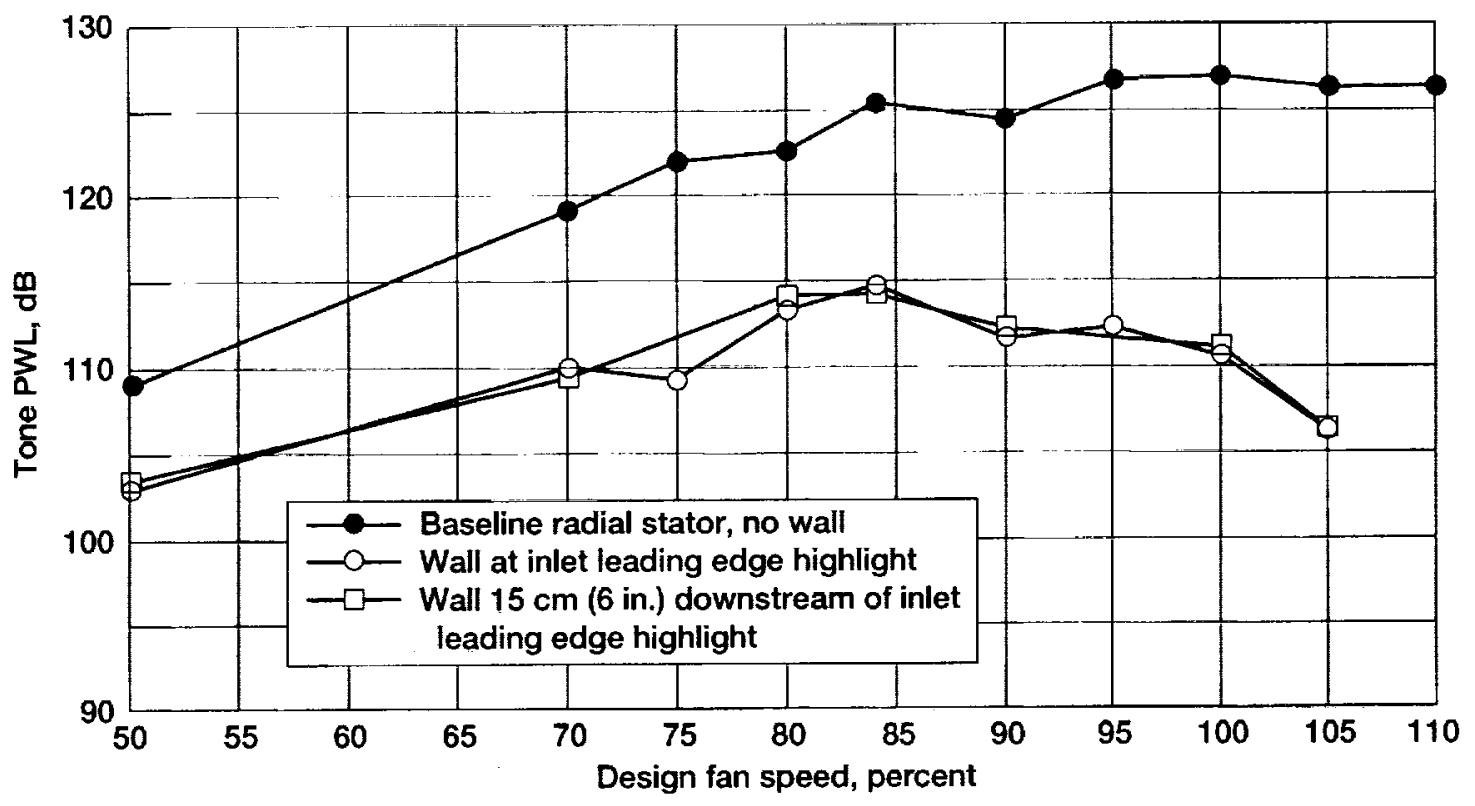

Figure 43.-Effect of barrier wall on $59 \mathrm{~Hz}$ narrowband 2BPF tone sound power level. (Data from translating microphone probe.) 
Davis Highway. Suite 1204. Arlington, VA 22202-4302, and to the Office of Managernent and Budget. Paperwork Reduction Project (0704-0188), Washington, DC 20503.

\begin{tabular}{|l|l|l} 
1. AGENCY USE ONLY (Leave blank) & 2. REPOAT DATE & 3. REPORT TYPE AND DATES COVERED
\end{tabular}

\begin{tabular}{|l|l|l|}
\hline 3. Technical Memorandum \\
\hline
\end{tabular}

4. TITLE AND SUBTITLE

5. FUNDING NUMBERS

Benefits of Swept and Leaned Stators for Fan Noise Reduction

6. AUTHOR(S)

Richard P. Woodward, David M. Elliott, Christopher E. Hughes, and Jeffrey $\mathbf{J}$. Berton

7. PERFORMING ORGANIZATION NAME(S) AND ADDRESS(ES)

National Aeronautics and Space Administration

Lewis Research Center

Cleveland, Ohio 44135-3191

WU-538-03-11-00

8. PERFORMING ORGANIZATION

REPORT NUMBER

E- 11382

9. SPONSORING/MONITORING AGENCY NAME(S) AND ADDRESS(ES)

10. SPONSORING/MONITORING

AGENCY REPORT NUMBER

National Aeronautics and Space Administration

Washington, DC 20546-0001

NASA TM-1998-208661

AIAA-99-0479

\section{SUPPLEMENTARY NOTES}

Prepared for the 37th Aerospace Sciences Meeting and Exhibit sponsored by the American Institute of Aeronautics and Astronautics, Reno, Nevada, January 11-14, 1999. Responsible person, Richard P. Woodward, organization code 5940, (216) 433-3923.

12a. DISTRIBUTION/AVAILABILITY STATEMENT

12b. DISTAIBUTION CODE

Unclassified - Unlimited

Subject Categories: 02, 07, and 71

Distribution: Nonstandard

This publication is available from the NASA Center for AeroSpace Information, (301) 621-0390.

13. ABSTRACT (Maximum 200 words)

An advanced high bypass ratio fan model was tested in the NASA Lewis Research Center 9×15-Foot Low Speed Wind Tunnel.

The primary focus of this test was to quantify the acoustic benefits and aerodynamic performance of sweep and lean in stator vane design. Three stator sets were used for this test series. A conventional radial stator was tested at two rotor-stator axial spacings. Additional stator sets incorporating sweep + lean, and sweep only were also tested. The hub axial location for the swept + lean, and sweep only stators corresponded to the location of the radial stator at the upstream rotor-stator spacing, while the tip axial location of these modified stators corresponded to the radial stator axial position at the downstream position. The acoustic results show significant reductions in both rotor-stator interaction noise and broadband noise beyond what could be achieved through increased axial spacing of the conventional, radial stator. Theoretical application of these results to acoustically quantify a fictitious 2-engine aircraft and flight path suggested that about $3 \mathrm{EPNdB}$ could be achieved through incorporation of these modified stators. This reduction would represent a significant portion of the $6 \mathrm{EPNdB}$ noise goal of the current NASA Advanced Subsonic Technology (AST) initiative relative to that of 1992 technology levels. A secondary result of this fan test was to demonstrate the ability of an acoustic barrier wall to block aft-radiated fan noise in the wind tunnel, thus revealing the acoustic structure of the residual inlet-radiated noise. This technology should prove valuable toward better understanding inlet liner design, or wherever it is desirable to eliminate aft-radiated noise from the fan acoustic signature.

14. SUBJECT TERMS

Noise; Swept and leaned stator; AST 36

16. PRICE CODE

\begin{tabular}{|c|c|}
\hline $\begin{array}{c}\text { 17. SECURITY CLASSIFICATION } \\
\text { OF REPORT } \\
\text { Unclassified }\end{array}$ & $\begin{array}{c}\text { 18. SECURITY CLASSIFICATION } \\
\text { OF THIS PAGE } \\
\text { Unclassified }\end{array}$ \\
\hline
\end{tabular}

NSN 7540-01-280-5500

19. SECURITY CLASSIFICATION
OF ABSTRACT
Unclassified

A03

20. LIMITATION OF ABSTRACT 
11 